NBER WORKING PAPER SERIES

DO NEIGHBORHOODS AFFECT CREDIT MARKET DECISIONS OF LOW-INCOME
BORROWERS? EVIDENCE FROM THE MOVING TO OPPORTUNITY EXPERIMENT

\author{
Sarah Miller \\ Cindy K. Soo \\ Working Paper 25023 \\ http://www.nber.org/papers/w25023 \\ NATIONAL BUREAU OF ECONOMIC RESEARCH \\ 1050 Massachusetts Avenue \\ Cambridge, MA 02138 \\ September 2018, Revised March 2020
}

The authors gratefully acknowledge the support of the Russell Sage Foundation Award 83-17-14. In addition, the authors thank Mark Shroder and Lydia Taghavi at the Department of Housing and Urban Development for providing the Moving to Opportunity Data, Cathleen Kelmar, Tushar Takkar, and Leila Agha for their assistance with the provision of the Experian credit report data, and Heather Lamoureux for assisting with the provision of the alternative credit data from Clarity Services, Inc. The authors also gratefully acknowledge useful feedback received from Joanne Hsu and seminar participants at the NBER Summer Institute Household Finance Group, the Western Finance Association Annual Meetings, the University of California-Berkeley Real Estate Group, New York University Stern-Real Estate, The Federal Reserve Board - George Washington University Financial Literacy Series, the University of Houston Finance department, the University of Oregon Finance department, and the University of Michigan Finance group. The results presented in this paper do not reflect the opinions of the aforementioned institutions, nor those of the National Bureau of Economic Research.

NBER working papers are circulated for discussion and comment purposes. They have not been peer-reviewed or been subject to the review by the NBER Board of Directors that accompanies official NBER publications.

(C) 2018 by Sarah Miller and Cindy K. Soo. All rights reserved. Short sections of text, not to exceed two paragraphs, may be quoted without explicit permission provided that full credit, including $\odot$ notice, is given to the source. 
Do Neighborhoods Affect Credit Market Decisions of Low-Income Borrowers? Evidence from the Moving to Opportunity Experiment

Sarah Miller and Cindy K. Soo

NBER Working Paper No. 25023

September 2018, Revised March 2020

JEL No. D12,D14,G41

\begin{abstract}
This paper isolates the causal impact of neighborhood environment on credit outcomes of lowincome borrowers by analyzing the participants of the Moving to Opportunity (MTO) experiment. MTO was a unique, large-scale experiment that offered families vouchers to move to better neighborhoods via randomized lottery. We find higher credit scores and use among those required to move to the lowest poverty areas as young children. For those who moved as adults, we find that better neighborhoods lead to a reduction of overdue debts and delinquencies, but only among those given unrestricted neighborhood choice.
\end{abstract}

\author{
Sarah Miller \\ Ross School of Business \\ University of Michigan \\ 701 Tappan Street \\ Ann Arbor, MI 48109 \\ and NBER \\ mille@umich.edu \\ Cindy K. Soo \\ University of Michigan, \\ Ross School of Business, \\ 701 Tappan Street, \\ Ann Arbor MI 48109-1234 \\ csoo@umich.edu
}


Borrowers in low-income neighborhoods tend to use and access credit very differently than those in high-income neighborhoods. Relative to higher-income borrowers, studies find low-income households are more likely to repeatedly borrow at high interest rates, use high-interest credit products such as payday loans, be categorized as high-risk or sub-prime borrowers, and have limited access to formal credit 1 The observed borrowing differences across poor and non-poor households raise alarming concerns for policies aimed at ensuring equal credit access and preventing discriminatory lending within low income neighborhoods. Disentangling whether it is the neighborhood or the borrower, however, that drives these behaviors is challenging empirically. Individuals select into their neighborhoods based on their own unobservable tastes and characteristics, which may in turn impact their financial decisions.

In this paper, we overcome this challenge and isolate the causal impact of neighborhoods on the borrowing behavior of low income households by linking participants of the Moving to Opportunity (MTO) experiment to nearly two decades of credit report data. The MTO experiment was a unique, large-scale randomized controlled trial conducted by the Department of Housing and Urban Development between 1994 and 1998. This experiment randomized individuals living in low-income subsidized housing projects into one of two treatment groups. The first group, called the Experimental group, received a voucher that required participants to move to a neighborhood with a less than 10 percent poverty rate. The second treatment group, called the Section 8 group, received an unrestricted Section 8 voucher, which provided the same rent subsidy but allowed the recipient to move to a neighborhood of her choice. The MTO experiment was designed to measure the impacts of these treatments relative to a control group of families that were currently living in government subsidized public housing in high poverty ( $>40$ percent) neighborhoods. As previously documented in Kling et al. (2007), Ludwig et al. (2012), Chetty et al. (2016), and others, being randomized into either treatment group resulted in a substantial reduction in neighborhood poverty rate.

Prior literature provides support for several channels through which neighborhood environment may impact credit outcomes. A number of studies highlight the positive impacts neighborhoods could have on behavior through peer effects, either through social learning or mimicking of better

\footnotetext{
${ }^{1}$ See for example Rhine et al. (2006), Dobbie and Skiba (2013), Brevoort et al. (2015), Adams et al. (2009), Miller et al. (2018) and Finkelstein et al. (2012))
} 
norms (Gross and Souleles (2002), Duflo and Saez (2012), Bursztyn et al. (2014), Lieber and Skimmyhorn (ming)). Better neighborhoods could also directly impact outcomes by simply facilitating greater local access to mainstream financial institutions while simultaneously distancing borrowers from the influence of local high-cost subprime lenders. At the same time, studies also suggest better neighborhoods could lead to overborrowing through peer pressure to "keep up" with the consumption of their higher-income neighbors (Campbell and Cochrane (1999), Bernheim (1994)). Even in the absence of peer effects, lower poverty neighborhoods could impose higher costs of living while simultaneously disrupting informal lending support networks. Finally, neighborhoods could indirectly impact credit outcomes if they lead to improvements in other dimensions, such as earnings.

Our results show that neighborhoods impact credit outcomes of low-income households, through both direct and indirect channels. Prior studies of MTO document increased earnings into adulthood among the youngest children of MTO, but consistently find zero effects on earnings of adults and older children who moved to better neighborhoods. Thus if neighborhoods impact credit solely through income, we would expect to find impacts on credit outcomes among those who moved as young children only. We find, however, that adults who were allowed to select the neighborhood they moved to significantly reduce their overdue debt and delinquencies. Our additional analysis suggests that requiring adults to move to the lowest poverty neighborhoods imposes higher consumption costs that outweigh debt reduction benefits of moving. Importantly, these results uncover the first economic benefits of better neighborhood environment among adults and older children. Prior MTO studies had previously concluded that moving had no detectable benefits on the economic outcomes of adults, and thus focused on the benefits to young children.

Our analysis first examines the impact of the MTO neighborhood experiment on the long-term use of credit and creditworthiness. We find that younger children who moved to the lowest poverty neighborhoods experience the greatest increases in use of credit and credit score into adulthood. Among this group, voucher usage increased credit scores approximately 11 points relative to the control group. This increase in credit score was accompanied by a meaningful impact on credit limits, credit use, and credit availability. Participants randomized to Experimental families early in childhood are approved for $\$ 821$ more in credit limits in adulthood, or $62 \%$ more relative to the control group mean. They utilize more credit and also have more revolving credit available. 
Applying a 'back of the envelope' calculation using estimates from recent studies that assess the effect of income on credit scores, we find that approximately half of the improvements in credit score are likely to be attributed to the observed income increases experienced by this group. We find similar impacts, although of smaller magnitude, among younger children within Section 8 families who also moved to better neighborhoods relative to the control group, but did not experience as large of a reduction in neighborhood poverty rate as the Experimental families.

Inconsistent with an income channel, however, we also find significant impacts on the repayment of debts and delinquencies among adults. This is in contrast to previous MTO studies, which have essentially found no economic benefits of moving to a low poverty neighborhood among those who moved as adults. Interestingly, we only find these improvements among adults who were allowed to choose the neighborhood they moved to. Adults who moved within this Section 8 treatment group have $\$ 333$ or $35 \%$ less in amounts more than 30 days overdue relative to the control group average. We also find that adults who moved to better neighborhoods of their choice owe $\$ 245$ or $66 \%$ less in overdue taxes, and $\$ 280$ or $42 \%$ less debts in court judgments relative to the control group mean. This reduction in debt is significant in magnitude given that earnings in this group are less than $\$ 14,000$ (Chetty et al. (2016)). We find similar reduction in delinquent debts, although with less precision, among older children who moved within Section 8 families. We do not find any statistically significant effects on delinquency among those in this age group who were randomized to the Experimental group.

Because of the low-income profiles of the MTO sample, we further evaluate whether participants use alternative subprime credit options such as payday loans. Payday loans are short-term, noncollateralized small loans that coincide with the payday of a borrower's employer. These loans typically come with very high fees ranging from $\$ 10$ to $\$ 20$ per $\$ 100$ borrowed. We find that younger children within the Section 8 voucher group show the largest and most significant reductions in payday borrowing. Younger children within families assigned to Section 8 vouchers borrow about $50 \%$ less in payday loans annually relative to the control group.

We pursue further analysis to explore the direct channels through which neighborhoods may have impacted our results. First, we explore peer effect channels by using a large 4 million random sample of credit reports to richly characterize the residents in zip codes where MTO participants lived between 2001 and 2017. We find that participants who received vouchers both as adults and 
as young children live in neighborhoods in adulthood where residents have higher credit scores and used greater amounts of credit relative to the control group. Since both age groups experienced significant changes in peers, it is somewhat surprising that the credit scores and use of credit measures only improve for those randomized as young children, as the existing literature on peer effects (Fay et al., 2002; Brown et al., 2008, e.g.) might have predicted that all participants would behave more like their neighbors after being exposed to the new peer group.

The fact that we do not observe similar debt reductions among adults in the Experimental group suggests that the requirement to move to very low poverty neighborhoods incurs potential negative impacts that dominate any positive neighborhood impacts gained by adults who were able to choose their neighborhood within the Section 8 group. Utilizing our 4 million panel data set further, we test whether neighborhoods adults in the Experimental group moved to show evidence of higher costs of living or expenditures. Consistent with higher costs of living or external habit formation models, we find that adults who were required to move to the lowest poverty neighborhoods also move to neighborhoods where peer expenditures and credit utilization rates are higher.

Finally, we use additional data from the Census Business Patterns to examine whether MTO participants moved to neighborhoods with a greater number of physical banks or payday loan stores. We observe that younger children in the Section 8 group who reduced their payday loan usage also reside in zip code with fewer payday loan stores in adulthood. This suggests that the physical presence of such intermediaries may be an important channel through which neighborhoods affect use of payday loans. We do not, however, find that MTO adults or older children move to zip codes with more traditional lending institutions or fewer payday loan stores. Note that this does not imply that neighborhoods do not impact credit access through other credit supply channels, but does suggest that the physical number of traditional bank branches located in a zip code is not driving the reductions in debts we observe across adults who move to neighborhoods with Section 8 vouchers.

Our work is the first to isolate a causal impact of neighborhood environment on credit outcomes of subprime, low-income households. Understanding the extent to which neighborhoods can affect credit outcomes is crucial to policies that aim to improve subprime borrowing behavior by altering neighborhood characteristics. We find better neighborhood environment does have significant impacts on credit outcomes, but that these effects are not uniform across borrowers. Younger children 
who move to the lowest poverty neighborhoods in early childhood experience improvements consistent with channels of income and peer effects: among this group, we find the greatest increases in credit scores, credit limits, and mainstream credit use. For those who moved as adults, we find that those who were allowed to choose the neighborhood they move to are able to significantly reduce their overdue debts and delinquencies. However, despite this reduction in delinquencies, they do not experience statistically significant increases in credit scores or credit limits. Our work is consequently the first to document positive impacts of neighborhoods on economic outcomes among adults in the MTO experiment. Our findings caution, however, that moving to the lowest poverty neighborhoods can impose costs that overwhelm the positive impacts on older children and adults without additional assistance. These results are particularly relevant for policymakers considering the trade offs surrounding whether or not to encourage families to choose certain neighborhoods that researchers believe are beneficial to young children, as has been implemented in a recent high profile experiment by Bergman et al. (2019).

The paper is organized as follows. Section I provides background and describes our data. Section II outlines our hypotheses and proposes mechanisms through which neighborhoods could affect credit outcomes. Section III describes our empirical analysis and presents our main results. Section IV revisits Section II and discusses which hypotheses are consistent with our results. Section V provides alternative specifications, additional results, and robustness checks. Section VI concludes.

\section{Background and Data}

\section{A. The Moving to Opportunity Experiment}

The Department of Housing and Urban Development (HUD) was authorized by Congress in 1992 to conduct a unique large-scale experiment across five U.S. cities named the Moving to Opportunity (MTO) experiment. The project aimed to address whether moving from a high to low poverty neighborhood would improve the socioeconomic prospects of low-income families. From 1994 to 1998, HUD randomly allocated rental assistance vouchers to households with children living in Baltimore, Boston, Chicago, Los Angeles, and New York. Participation in the program was voluntary, but due to excess demand for vouchers, the MTO program was able to allocate vouchers by randomized lottery. Families had to be currently residing in a high poverty census tract $(>40$ 
percent) and living in a public housing project or Section 8 assisted housing to apply.

MTO randomly assigned participating households into one of three groups: the Experimental group, the unrestricted ("Section 8") voucher group, and a control group. The Experimental group received housing vouchers that could only be used in Census tracts with poverty rates less than 10 percent in the first year. This group also received additional intensive housing relocation counseling services. The Section 8 voucher group received regular unrestricted vouchers that had no location constraint. To be eligible for the experiment, families had to be already living in public housing or receiving housing assistance; the control group simply experienced no change in their housing assistance. Note that this eligibility criteria implies that the vouchers provided by the MTO program did not represent any additional income subsidy in housing assistance, but rather enabled families the opportunity to move out of their current housing location. The MTO experiment enrolled a total of 4,608 low-income families into its program.

As intended, the MTO experiment created significant variation in the types of the neighborhood in which adult participants lived and their children were raised. Those who received and used the Section 8 voucher moved to lower poverty neighborhoods relative to the control group and the Experimental group was more likely to reside in lower poverty neighborhoods relative to both the control group and the Section 8 group (see, e.g., Kling et al. (2007)). These effects on neighborhood are persistent: Chetty et al. (2016) find these relative neighborhood poverty rates are true for children both during childhood and into adulthood as well $?^{2}$

Initial studies of MTO found no effect of being randomized into the Experimental or Section 8 group on adult economic self-sufficiency or earnings, and mixed results for children, with some positive effects detected for female children but negative effects on male children (Kling et al., 2007). Follow-up on longer-term effects found that adults in the MTO treatment groups had improved health as evidenced by lower rates of obesity and elevated glycated hemoglobin (a measure of diabetes risk) (Ludwig et al. 2011). Additional long-term follow up found that those in the MTO

\footnotetext{
${ }^{2}$ Follow up studies on mobility patterns of MTO show that participants within both treatment groups continued to live in neighborhoods with on average lower poverty rates relative to the control group. MTO only required Experimental voucher recipients to stay in their initial lower poverty neighborhood for one year. While the majority of both treatment groups had moved again by 2002, voucher recipients of the Experimental voucher continued to live in neighborhoods with lower poverty rates relative to those who received the Section 8 vouchers with no location constraint (Orr et al. (2003)). Chetty et al. (2016) show that children of families who received the Experimental vouchers lived in neighborhoods with on average lower poverty rates than those within families who received Section 8 vouchers, and similarly those within the Section 8 group lived in neighborhoods with lower poverty rates relative to the control group.
} 
treatment groups reported improved subjective well-being and suggestive improvements in mental and physical health, but no improvements in labor market outcomes (Ludwig et al., 2012). Finally, a study using tax data analyzed the long-term impacts of MTO on both children and adults who were involved in the experiment (Chetty et al., 2016). Consistent with previous research, the authors found null effects on earnings for those who participated in MTO as adults. However, they found substantial improvements along several dimensions for children in the treatment groups who were younger than 13 at the time of random assignment. In particular, they find an approximately 30 percent increase in earnings, a 2.5 percentage point increase in college attendance rates, and lower single parenthood rates for children in the Experimental group. The authors find no effect for children who were older at random assignment.

\section{B. $\quad$ MTO Data}

The data used in our analysis relies on two sources. First, we obtain information on all MTO participants, including both those who were adults and children at the time of the experiment, directly from HUD. Baseline information collected on MTO participants is extremely thorough and includes variables such as employment status, income, government benefits, neighborhood characteristics, and reasons for participating in MTO. These baseline surveys also report details on children within each MTO household, including school behaviors or learning disabilities for older children and birth weight for younger children. Detailed descriptions of all variables can be found in Sanbonmatsu and Lindau (2011).

In contrast to Chetty et al. (2016), our data do not contain information on the exact date of random assignment for each participant. Instead, we see the site at which each individual is associated, and we know the range of dates during which random assignment occurred at each site. We therefore classify individuals as being, e.g., under 13 at random assignment if they were under 13 at the midpoint of their site's random assignment period. Although this will likely result in some mis-classification between older and younger children, this assignment mechanism should capture the broad age groups we seek to define (i.e., child or adult; younger or older children).

Following prior studies on MTO, we apply sampling weights to address changes in random assignment ratios during course of the MTO program (Kling et al. (2007), Chetty et al. (2016)). Each individual is weighted by the inverse of his or her probability of being assigned to the Experimental 
group. See Orr et al. (2003) for full details on sample weights construction.

\section{Traditional and Alternative Credit Data}

We obtain individual-level credit reports for MTO participants from Experian, one of the three major credit bureau agencies. Our credit report data contain a snapshot of a consumer's credit profile observed annually from 2001 to 2017 in June of each year. Credit reports were matched by name and social security number (SSN), which were provided by HUD to Experian. Data was matched through a blinded process in order to protect privacy and all personally identifying information was removed from the credit records before being provided to the authors for analysis.

Our data allow us to observe adult MTO participants for up to 17 years. Those who were children only enter the data set as adults, and most commonly around the age of 20 according to Brevoort et al. (2015). Thus, all children will be eligible to enter the dataset by 2017, but we will only observe credit outcomes for children in later years.

We further link MTO participants to a novel data set provided by Clarity Services, Inc., a subsidiary credit reporting agency of Experian that specializes in the subprime consumer market. Clarity supplements information on alternative credit behavior-in particular, applications for and use of payday loans-that is not available from traditional reporting agencies such as Experian ${ }^{3}$ Given the low-income population of MTO participants, these types of alternative lending sources may be particularly relevant. The Clarity payday loan data are provided to us at the loan level, allowing us to see the repayment history and outcomes for specific accounts for the years 2014 to 2017. We also observe inquiries for payday loans over the same time period. We aggregate this information to the year level to conduct our analysis.

Clarity data includes over 60 million consumers, and covers over $70 \%$ of non-prime consumers across the United States. However, despite their broad coverage, Clarity only obtains this information for loans originating with lenders who use their underwriting services, so their database may

\footnotetext{
${ }^{3}$ Payday loans are a short-term, single payment loans named after the fact that borrowers scheduled loan repayment coincides with their next payday from their employer. Payday loans are unsecured by any collateral, but require evidence of a regular income and a checking account. Lenders will typically accept a pay stub or Social Security check as income evidence. Loan amounts are typically very small, ranging from $\$ 50$ to $\$ 300$, and very short-term, two to four weeks, depending on the timing of the borrowers income. Fees associated with these single payment loans are typically very high relative to the loan amount, ranging from $\$ 10$ to $\$ 20$ per $\$ 100$ borrowed. While loan maturation is usually set to the borrowers next payday, lenders often provide the option for borrowers to roll over or re-borrow within a few days of the due date.
} 
not include information on all products used by each borrower. This is an important caveat to our analysis because effects on payday lending may be present but not observable in the Clarity data. Nevertheless, we believe Clarity offers the best existing coverage of payday borrowing behavior across the U.S..

In addition, we note that online payday lenders are over-represented in Clarity's database as they are more likely to need external information when processing loan applications. These lenders provide an interesting opportunity to evaluate the extent to which neighborhood affects borrowing beyond physical access to brick-and-mortar storefront lenders.

\section{Match Rate and Summary Statistics}

We link the MTO data to administrative credit bureau and alternative credit records by name and social security number (SSN). A total of 15,892 individuals participated in MTO, and HUD provided valid SSNs for 11,512 of these participants, including adults and children 4 Of those SSNs, we matched $95.2 \%$ (10,958 individuals) to Experian and $74 \%(8,515)$ to the alternative Clarity credit data. Match rates to Experian are similar across all three treatment arms as demonstrated in Table A1 note that the match rate listed for the control group contains the overall match rate, including those without valid SSNs. It is also important to note that individuals only appear in the Clarity credit data if they have used a subprime loan product cover by this dataset; we therefore have no reason to expect a $100 \%$ match rate for this dataset.

Although most individuals with a valid social security number were matched to the Experian database, younger participants are typically observed for fewer years. For example, an individual who was age 5 when his family received a voucher in 1996 might not have a credit report until age 20, in 2011. Such an individual would be observed for seven years (2011 to 2017), while his parents might be observed for 17 years (2001 to 2017). On average, we observe matched participants for 8.6 years; those who were adults at random assignment we observe for 11 years on average; those who were under age 13 at random assignment we observe for 6 years on average. As shown in Table A1. the number of years for which we observe an individual does not vary across treatment arm.

The original and follow-up MTO evaluations ensure that treatment and control groups are

\footnotetext{
${ }^{4}$ The number of valid SSNs was provided to the authors by Experian and validity was determined through Experian's internal analysis. The authors themselves did not have direct access to the SSN variable.
} 
balanced across baseline characteristics. We replicate balance tests for our linked MTO-credit sample, and find that treatment and control groups remain balanced. Out of the 52 baseline covariates from the original MTO study, we find 3 significant differences between groups at the $p<0.05$ level and 3 additional differences significant at the $p<0.10$ level. Given that we do not adjust these t-tests for multiple comparisons, these differences are consistent of what we would expect with random assignment.

Table A1 presents summary statistics and results of the balance tests for a key set of covariates $5^{5}$ MTO families came from very poor socioeconomic conditions. Table A1 shows that for our matched sample, less than a quarter of the heads of household were employed, less than 40 percent had completed high school, and most (80 percent) were receiving government assistance. Nearly a third of the families had a teenage birth, and most had never been married. Nearly half reported being a victim of a crime just 6 months prior to enrolling in MTO, and more than three-quarters reported that their primary reasons for moving was to get away from gangs or drugs. Consistent with the original MTO studies, more than 90 percent of the household heads were female and African-American or Hispanic.

\section{Empirical Hypotheses and Framework}

Neighborhood effects are notoriously difficult to estimate because individuals endogenously sort into neighborhoods based on unobserved characteristics. The MTO Experiment is a unique setting to observe changes in individuals' proximity to financial institutions and modifications to peer groups in a robust and controlled setting. At the same time, moving neighborhoods changes a bundle of characteristics simultaneously. While the MTO experiment allows us to identify a causal effect of neighborhood changes, gaining an understanding of which channels neighborhoods may move through to impact credit decisions is important and informative for policy design. In the following, we outline channels through which MTO neighborhood changes can impact credit decisions to inform any potential effects we estimate in our analysis.

\footnotetext{
${ }^{5}$ Balance tests for all 52 covariates are available upon request.
} 


\section{A. Direct Effects of Neighborhood through Credit Demand}

We begin by considering first order direct impacts neighborhoods may have on credit outcomes by altering an individuals' demand for credit. First, neighborhoods could affect demand for credit through peer effects. Studies have shown peer effects have causal effects on individual stock market and retirement investments (Brown et al. (2008), Hong et al. (2004), Duflo and Saez (2012), Bursztyn et al. (2014)). Models of peer effects applied to the stock market posit that social interaction may serve as a mechanism for observational learning or information diffusion (Hong et al. (2004); Banerjee (1992); Ellison and Fudenberg (1993)), and experimental evidence shows that unsophisticated investors in particular are strongly influenced by such "social learning" (Bursztyn et al. 2014). Moving to a better neighborhood has the potential to expose MTO participants to peer groups that influence their credit decisions through the same social mechanisms. This channel is supported by studies of payday lending that find evidence that some low income borrowers improve behavior in response to information disclosure interventions (Bertrand and Morse (2011), Burke et al. (2016)). Better neighborhoods may provide low income borrowers with the peer groups to learn about different credit products or provide better information to avoid high interest credit products. At the same time, if neighbors' behavior is not observable to participants, these peer effects may be muted (Lieber and Skimmyhorn, ming).

Alternatively, MTO participants may simply try to mimic the behavior of others in their neighborhood for the purpose of social conformity without any information transmission occurring. While information transmission via peers networks is likely to lead to "better" behavior, a mechanism that implies MTO participants will simply behave more like their neighbors could be positive or negative, depending on the behavior of their neighbors. While "social information" models of peer effects suggest that moving to a neighborhood with more financially sophisticated neighbors could improve borrowing behavior, models of conformity or external habit formation (Abel (1990); Bernheim (1994); Campbell and Cochrane (1999)) suggest peers could have the opposite effect. By encouraging consumption at the level of their higher-income neighbors, moving to a low poverty neighborhood could generate a "keeping up with the Joneses effect" that may lead individuals to take on debt in order to increase consumption to unsustainable levels (Agarwal et al., 2019, Bertrand and Morse, 2016). 
Even in the absence of peer effects, moving to a lower poverty neighborhood may also directly raise living costs, or encourage investments in children that require greater spending. Of the MTO participants, nearly three-fourths of the participants were young, single mothers where moving to a low poverty neighborhood may have increased basic costs of child care. Follow up surveys of MTO participants who moved to the lowest poverty neighborhoods also lost access to public transportation, free recreational activities, health care, shopping, and churches relative to those who stayed in more central locations with higher poverty shares (Orr et al. (2003)). Thus if moving to a low poverty neighborhood raises costs, we might expect MTO then to have negative impacts on credit outcomes, especially for adults who were required to move to the lowest poverty neighborhoods and bear the greatest burden of the initial move 6

\section{B. Direct Effects of Neighborhood through Credit Supply}

Moving neighborhoods also has the potential to directly impact credit supply by changing a borrower's physical access to lending institutions. This is particularly relevant for low income borrowers, where a central issue in policy debates has been over access to finance, both through the lack of availability of traditional credit and the prevalence of subprime credit products such as payday loans across low income neighborhoods. A better neighborhood has the potential to bring low income borrowers physically closer to traditional banks and put increased distance between borrowers and high-cost alternative or payday lenders. Exposure to financial institutions in childhood could also have life long impacts on the use of credit; for example, Brown et al. (2019) find that local exposure to formal banking instutitions early in childhood leads to long-term improvements in consumer credit outcomes. At the same time, moving to a very low poverty neighborhood can potentially result in losing informal family or friend lending networks that are difficult to maintain from a distance. Beyond changing the proximity of lending intermediaries, neighborhoods might also affect lenders' willingness to supply credit if positive peer effects make repayment more likely. Lenders may also be willing to lend more to those with higher incomes, which could be indirectly affected by the neighborhood environment, as described in the next subsection.

\footnotetext{
${ }^{6}$ Note that subsidy amount allotted for MTO vouchers were implemented in the same way as the current Section 8 voucher program in that there is a cost of living adjustment by metropolitan area, but not by neighborhood within MSA. Families who received vouchers with the location restraint additional counseling services to locate suitable housing, but not any other additional resources
} 


\section{Indirect Effects of Neighborhood through Improved Income}

We would also expect neighborhoods to impact credit indirectly through improvements in income and subsequent changes in liquidity constraints, which in turn affect credit score, willingness to lend, and demand for credit. To be eligible for the MTO experiment, participants had be to currently receiving public housing assistance. Thus, receiving a MTO voucher did not itself translate immediate cash liquidity relief.7 However, recent results Chetty et al. (2016) find increased earnings for participants who were moved to better neighborhoods as young children. Increased wealth or income has the potential to provide additional liquidity to repay debts or qualify for additional credit. In a recent study, Brown et al. (2019) find borrowers with subprime scores increase their credit utilization by 6.9 percentage points and reduce their debt-to-income ratio by 3.4 percentage points in response to a positive wealth shock. A number of studies also report positive correlations between income and credit scores (Beer et al., 2018), though credit bureaus do not use income as a direct input in their score calculations.

Both short and long-term studies of MTO have consistently found no effects on wages and earnings for participants who were adults at random assignment of the MTO experiment. Thus, we can use the disparate subgroup results on earnings to distinguish whether any impacts we identify are working through the income channel. If we detect effects on credit among those were children at random assignment but not among adults, wages and earnings likely play an important role. If we do find any impacts among those who moved as adults or older children, however, it is unlikely earnings serves as a channel for neighborhood effects on credit among these subgroups.

\footnotetext{
${ }^{7}$ To be eligible for the MTO experiment, control group families had to be already receiving housing assistance through public housing. Without a MTO voucher, families would have to otherwise give up their housing subsidy in order to move to a different unit or neighborhood. The MTO vouchers essentially lower the cost of moving by allowing families to relocate without giving up their current rental subsidy (Sanbonmatsu and Lindau (2011)). Both MTO treatment groups received standard Section 8 vouchers where the value of the vouchers are based on the 40th percentile of median rents within a city. Specifically, the voucher paid for the difference between 30 percent of household income and the citys Fair Market Rent, which was designated by HUD to be at the 40th percentile of rents within a city. So, for example, if a household made $\$ 500$ per month, and the Fair Market Rent was $\$ 800$ per month, the voucher would provide a subsidy of up to $\$ 650$ per month.
} 


\section{Empirical Analysis and Results}

\section{A. Empirical Framework}

In our baseline analysis, we compare financial outcomes in the Experimental group and the Section 8 group to the control group that did not experience an improvement in neighborhood quality with the following standard specification:

$$
Y_{i}=\beta_{0}+\beta_{1} \operatorname{Exp}_{i}+\beta_{2} S e c 8_{i}+\beta_{s}+\epsilon_{i}
$$

where $\operatorname{Exp}_{i}$ and $S e c 8_{i}$ are indicators for the Experimental or Section 8 arm, with the control group serving as the omitted category. We include site fixed effects $\left(\beta_{s}\right)$ to control for potential differences across treatment sites. In this model, $\beta_{1}$ and $\beta_{2}$ measure the differences between treatment groups and control group means. Because not all families in MTO used their voucher, this baseline specification measures the intent-to-treat (ITT) effect, i.e. the effect of being offered a voucher in the MTO program.

The ITT estimates of Equation (1) should understate the effect of using a voucher as not all families that were offered a MTO voucher actually used them. Therefore, we report treatment-ontreated (TOT) estimates across our outcomes in our main tables. Following prior studies on MTO, we instrument actual voucher takeup with the offer of a MTO voucher. We estimate:

$$
Y_{i}=\beta_{0}+\beta_{1} \operatorname{Exp}_{i}^{\text {Takeup }}+\beta_{2} S e c 8_{i}^{\text {Takeup }}+\beta_{s}+\epsilon_{i}
$$

where $\operatorname{Exp}_{i}^{\text {Takeup }}$ and $S e c 8_{i}^{\text {Takeup }}$ are now indicators for actually using the housing voucher. We estimate with 2SLS and instrument $\operatorname{Exp}_{i}^{\text {Takeup }}$ and $S e c 8_{i}^{\text {Takeup }}$ with $\operatorname{Exp}_{i}$ and $S e c 8_{i}$. In order to interpret these estimates as causal, we must assume being offered a MTO voucher only affects financial outcomes through actual takeup and there was no average effect on borrowing of being just offered a MTO voucher if the family did not use it. Families who chose not to move still received counseling services, but these services provided only housing search advice and excluded any general services that we think might affect credit outcomes. Given these assumptions, we interpret $\beta_{1}$ and $\beta_{2}$ of equation (2) as the causal effect of physically moving to a low poverty neighborhood or using a traditional Section 8 voucher (Angrist et al., 1996). 
Credit records contain a large number of outcomes measuring use of credit, credit worthiness, and delinquencies. Following Kling et al. (2007), we collapse our outcome variables into one summary index per topic of outcomes in order to reduce the number of hypotheses tested and to improve our power to detect effects if present. Outcomes are grouped into three broad "domains": use of credit and creditworthiness, delinquency behavior, and payday borrowing. We briefly describe these outcomes here; see the data appendix for additional information and descriptive statistics.

Our credit domain contains several outcomes. We include each consumer's credit score provided by Experian's Vantage Score, a model that is comparable to the Fair Isaac Corporation (FICO) credit scores. The score incorporates characteristics across a borrowers credit report including payment history, delinquencies, number of accounts, and credit applications to assess his or her likelihood to be over 90 days delinquent on loans. Vantage Scores range from 300 to 8508 and scores below 600 indicate subprime borrowers. We include the total credit limit across all credit cards active on a borrower's credit report and the total amount of credit available (i.e., unused). To measure use of credit, we examine total balance on all accounts, including non-revolving accounts such as mortgages, car loans, and student loans, and we examine the minimum monthly payment due across credit cards. It is important to note that, while higher levels of debt may be indicative of more engagement with formal credit markets, debt is not necessarily a "good" outcome for consumers. These results therefore do not necessarily show that this group is better off, only that they are more likely to borrow through formal channels that are reported to credit bureaus.

The delinquency index is comprised of 4 outcomes. First, we include the amount a borrower holds 30 days past due or more on open accounts. This would include, for example, an overdue credit bill. Second, we include the amount in tax liens, or overdue taxes. Third, we include the amount ordered to be paid by a court judgement. These judgments could concern, for example, unpaid rent cases or child support, and can be used to seize collateral and wages. Finally, we include amount of debt past due held by third party collection agencies. Debts held in collections are those that have been repeatedly pursued but unsuccessfully collected by lenders and finally sent to third party agencies for collection. Any amount of debt sent to third party collections can have a large negative impact on a borrower's credit score.

To examine payday borrowing, we consider the total amount borrowed annually across all

\footnotetext{
${ }^{8}$ This is based on the Vantage Score 3.0 model. Prior VantageScore models ranged from 501 to 900.
} 
payday loans, the amount borrowed across payday loans taken out online, payday amounts borrowed in person at physical storefronts, and the number of payday loan applications a borrower has.

Within these domains, we standardize all outcome variables into z-scores by subtracting the mean and dividing by the standard deviation of the control group. We then average these z-scores with equal weighting into one summary outcome measure, represented by $Y_{i t}$. This allows us to test whether the outcomes taken together as a whole indicate changes within these domains. Compressing multiple measures into a single index can also improve power if each component is a noisy measure of the same underlying concept. Our focus for these domains is on the sign and significance of the coefficients rather than directly comparing the levels across the different experimental arms. Components have been oriented so that a higher credit index indicates greater credit worthiness and credit usage, a lower delinquency index indicates reduced debts and delinquencies, and a lower payday index signals less payday usage.

We cluster all standard errors by family since the level of MTO random assignment occurred by family. P-values are based on a clustered bootstrap with 999 repetitions. Given the number of hypotheses we consider simultaneously, we may find a few false significant estimates based on sample probability alone. Thus, for the components of the indices, we calculate domain-wise error rate adjusted p-values and report these in square brackets below, using the methods described in Westfall and Young (1993). These p-values limit the probability of rejecting at least one true null hypothesis within each topic to be no more than $5 \%$ (for tests using a $95 \%$ confidence interval). We calculate these p-values using the algorithm outlined in Anderson (2012), which is discussed in more detail in the appendix.

Finally, we also conduct statistical tests as to whether the effect of voucher use is the same across age groups and treatment arms. We denote significance levels of these tests with two symbols: $\dagger$ indicates significance levels of a test for equality of the effect across children randomized under age 13 with each older age group within the same treatment arm, while $\diamond$ indicates significance levels of a test for equality of the effect across the Section 8 and Experimental arm among those in the same age group. Note that we do not adjust these tests for equality across groups for multiple comparisons. We also do not adjust our p-values for multiple comparisons in all Appendix Tables, which we consider exploratory. 


\section{B. Summary Impacts}

Table Iprovides a summary of our analysis across our 3 broad domains: credit, delinquency, and payday usage. Across all participants, our results show that credit usage increased for those who received Experimental vouchers and were required to move to the lowest poverty neighborhoods. We do not find statistically significant improvements in delinquency or payday across all participants in the Experimental group. We do, however, find significant reductions in delinquencies and payday usage among participants who received Section 8 vouchers and were allowed to choose the neighborhoods they moved to with no location constraint. While the estimate for the credit index is positive across all Section 8 participants, the results are not statistically different from 0 and our confidence intervals do not allow us to rule out increases in credit use as large as 0.06 standard deviations or decreases in credit use as large as 0.02 standard deviations.

The subsequent columns of Table $\square$ reveal that these differential impacts are driven by varying effects across different age subgroups. We split our analysis on MTO participants into 3 age subgroups: those were age 18 or older at random assignment (adults), those who were children by older ages of 13-17 at random assignment, and by those who were younger children under the age of 13 at random assignment.9 The first row of Table 1 shows that credit index estimates are strongly positive and significant for young children who moved with the Experimental vouchers, and positive and significant at the 10 percent level for those within the Section 8 treatment group. Estimates for adults and older children are not significantly different than zero. As noted above, we orient signs such that a positive estimate indicates increased traditional credit usage, availability, and creditworthiness from the underlying outcomes.

In contrast to credit, our results show that the significant reductions in delinquencies within the Section 8 voucher group are driven by the adult and older children subgroups. For delinquencies, we orient signs such that a negative estimate indicates a reduction in overdue ebts and delinquent payments. Columns 4 and 6 of Table【 show that estimates for the delinquency indices are negative and highly significant for adults and older children who moved within the Section 8 voucher. This is the first evidence from the MTO experiment that documents a significant improvement in any

\footnotetext{
${ }^{9}$ Note that our outcomes for children are measured when these children are adults, beginning from when we observe their first credit report. Thus, this could be a different age per child participant depending when they incur their first credit report. We have also restricted our analysis such that we estimate our model holding fixed adult age across child participants and find similar results (see Section V.
} 
economic outcome for adults and older children MTO participants. For younger children, estimates for the delinquency index are negative across both treatment groups, but significant only for younger children within the Experimental treatment group.

Our estimates for the payday index show that reductions are driven primarily by participants in the Section 8 voucher group. Results are negative across all age groups, but only statistically significant among younger children within the Section 8 voucher group. For other age groups and treatment arms, our confidence intervals do not allow us to reject moderately sized decreases or increases in this outcome. In the following tables we present the estimates for the individual outcome underlying each of our overall indices.

\section{Impacts of MTO on Use of Traditional Credit and Creditworthiness}

Table II presents the TOT estimates for each individual outcome underlying the summary credit index 10 The credit index is comprised of 5 components: credit scores, credit limits, total balance, monthly payments, and credit availability. Note that all of these measures are equilibrium credit market outcomes that reflect both borrower's credit demand and lender's willingness to supply credit.

For younger children, the mean credit score of the control group is 495.6. Vantage Scores below 500 are considered "deep subprime," so the control group mean is only just below this critical level. We find that using an Experimental voucher increases credit scores by 11 points, indicating an improved ability to borrow for this younger group relative to the control. The estimate is significant at the 5 percent level, and the symbol $\diamond$ indicates that it differs significantly from the effect observed in the Section 8 group at the 10 percent level. Prior studies have found that a $2 \%$ increase in credit scores for subprime borrowers leads to significant differences in credit use and borrowing behavior (Gross et al. (2018), Dobbie et al. (2017)), suggesting that this improvement in score is potentially large enough to alter this group's ability to borrow. Furthermore since credit history is a component of credit score, we would expect impacts to accumulate as younger individuals continue to build their credit history; see Section $\nabla$ for more evidence on these trajectories. We also find that younger children in the Experimental group have significantly higher credit scores than younger children

\footnotetext{
${ }^{10}$ ITT estimates can be found in the Appendix.
} 
who moved with Section 8 families, indicated by the diamond symbol following the coefficient ${ }^{11}$ It is also notable that the effect on credit scores from moving to a low poverty neighborhood as a child is comparable to other effects documented in the literature, such as the impact of the removal of a bankruptcy flag (Gross et al., 2018) or the effect of receiving health insurance through a government program (Brevoort et al., 2019), indicating that effects of this magnitude are plausible.

In contrast to what we observe among the Experimental group, we do not find any improvements in credit scores for younger children assigned to the Section 8 group relative to the control group mean, and our standard error allows us to rule out increases in credit score larger than 8 points. The lower panels show that we similarly find no statistically significant effect on credit scores for older children or adults across both treatment groups. Estimated coefficients for older children and adults within the Experimental group are actually negative, though these are not statistically significant, and our confidence interval excludes improvements in score larger than about 7 points (for older children) or 8 points (for adults). Estimates of the effect on those randomized as older children in the Experimental group differ significantly from the effect estimated among those who were randomized to the Experimental group as young children at the $10 \%$ level, as indicated by the symbol $\dagger$.

Column 3 presents the MTO neighborhood impacts on credit card limits aggregated across all open cards. The average credit limit across all ages in the control group is $\$ 2930$, indicating a fairly credit constrained sample; the typical adult in a credit reporting database has a credit limit of over $\$ 20,000$ on their combined credit cards (Gross et al. (2018), Miller and Soo (2018)). Younger children of the control group have lower average credit limits of $\$ 1,333$. Our TOT estimates indicate that moving to a low poverty neighborhood with an Experimental voucher generated an $\$ 821$ increase in credit limits. This represents a $62 \%$ increase over the control group mean. Younger children within the Section 8 group also experience significantly higher credit limits relative to the

\footnotetext{
${ }^{11}$ We follow Experian's coding of assigning "unscorable" reports a very low credit score of 4 . Our analysis therefore embeds within it both the effect of moving from the "unscorable" range to the "scorable" range and the effect of increased scores among those who are already scored. Alternatively, we can conduct this analysis using two separate outcomes: a binary variable equal to 1 if the participant has any credit score, and the average credit score among those who are not unscorable. When we do this, we find that those assigned to the Experimental group at young ages experience a decrease in the probability of being unscorable of about 0.8 percentage points, or $18 \%$ relative to the control group mean. The effects on average score remain positive and statistically significant, but smaller in magnitude if we exclude the unscorable. The interpretation of the effect on average credit score when conditioning on the credit file being "scorable" is complicated due to the selection of participants into the scorable range; for that reason, we focus on the version that imputes a low score for unscored participants throughout our analysis.
} 
control group mean. The TOT estimates for Section 8 younger children show an increase of $\$ 366$ with $p<0.10$ level, which is $20 \%$ greater than the control group mean.

We find young children who moved with MTO vouchers also appear to be more active users of mainstream credit than the control group. Column 4 reports the effect of MTO on the total balance across all accounts. This includes both revolving and non-revolving accounts such as mortgages, auto loans, and student debt. The The TOT estimate shows that Experimental voucher use resulted in $\$ 4,298$ or $62 \%$ higher balances relative to the control group mean of $\$ 6,742$ on average. We find significant effects of voucher use at the $p<0.10$ level for young children of Section 8 families, across a range of $\$ 898$ to $\$ 3,642$ greater. Consistent with credit scores and credit limits, we do not find any impacts on total balance across adults or older children among either MTO treatment group.

Column 5 reports the minimum monthly payment due across credit cards. These results also indicate that participants in the Experimental group are more active mainstream credit card users relative to the control group. The average younger child who grew up within a control group family has a monthly payment of approximately $\$ 120$. Estimates show that across younger children using an Experimental voucher results in monthly payments that are $\$ 46$ or about $37 \%$ greater than the control group mean. Younger children randomized into Section 8 group also results in significantly higher payments of than the control group, of approximately $\$ 26$ or $22 \%$ higher. While these effects are not as large as those observed among the Experimental group, estimates are not statistically different between the two treatment groups within the younger children subgroup. Again, we do not find moving to better neighborhoods has any statistically significant impact on monthly payments across adults or older children randomized into either MTO treatment group, although our confidence intervals are fairly wide.

Finally in column 6, we examine the amount of revolving credit MTO participants have available relative to those in control group families. We examine this outcome separately to evaluate whether individuals are credit constrained. Although our results indicate that younger children in the Experimental group have higher limits, we also see from their monthly payments in column 5 that they borrow more. Available revolving credit captures whether there is remaining credit available after accounting for the amount borrowed. We find that younger children not only qualify for greater credit limits and are more active users of credit, but they also maintain their payments such that they have significantly more credit available to use across credit cards. Column 6 shows 
that younger children who moved with the Experimental vouchers are nearly $80 \%$ higher relative to a control group mean of $\$ 829$. The stars following the coefficient indicate a significance at the $5 \%$ level, and the subsequent two daggers indicate that this estimate is also statistically different and significantly higher than our estimate for younger children within the Section 8 treatment group at the $5 \%$ level. Nonetheless, we also find younger children who moved with Section 8 families still have $44 \%$ greater revolving credit available than younger children within the control group.

\section{Impacts of MTO on Delinquency}

Table III presents the TOT estimates for each individual outcome underlying the summary delinquency indices in Table I The first column reports the same delinquency indices reported in Table I. As noted above, in contrast to our results on credit we find the benefits of the MTO program to delinquencies are instead concentrated across adult and older children subgroups who moved with Section 8 vouchers. As discussed, participants who moved with Section 8 vouchers were allowed to use the voucher in any neighborhood of their choosing, while those who received the Experimental voucher were required to move to a neighborhood of poverty levels below 10 percent.

Column 2 of Table III reports individual estimates on debts a borrower holds 30 days past due. We only find statistically significant reductions in amounts past due across adults within the Section 8 treatment group. Adults within the control group hold approximately on average $\$ 945$ in past due debt across our sample period. This debt is of relative significant magnitude given that Chetty et al. (2016) finds annual reported earnings of less than $\$ 15,000$. Our estimates find that adults who moved with a Section 8 voucher have 35\% (\$333) less overdue debt than the control group average. Older children who were assigned to the Section 8 group hold about $\$ 400$ less in amounts overdue, although it is not statistically significant once the multiple comparison adjustment is applied $(\mathrm{p}=0.192)$. Estimated effects are also negative for adults and children assigned to the Experimental group, but not statistically significant. Estimated effects for younger children are actually positive, indicating they hold higher debts than the control group average but estimates are not significant.

Column 3 examines the effects of MTO on tax lien amounts, or overdue taxes. Like overdue debts, we only find statistically significant estimates among adults within the Section 8 voucher

\footnotetext{
${ }^{12}$ ITT estimates can be found in the Appendix.
} 
group. TOT estimates show that an adult that moved with a Section 8 voucher holds $\$ 101$ less or $66 \%$ decrease relative to the control group average tax liens. Children across any of the treatment groups do not show any significant impacts on tax lien amounts, though children in the control group owe relative small amounts in taxes, less than $\$ 150$.

Column 4 examines the impacts of MTO on debts that have been taken to court. Adults in the control group owe approximately $\$ 671$ in judgment amounts on average, while older children hold slightly less at $\$ 625$ and younger children owe much less at $\$ 216$. We again find significantly lower debts among adults in the Section 8 voucher group relative to the control group. Our TOT estimates show adults who took up the Section 8 voucher owe $\$ 280$ less $-42 \%$ less than the control group. Impacts are significant at the $10 \%$ level. Adults assigned to the Experimental group also have lower debts relative to the control group, though estimates are no longer significant once adjusted for multiple comparisons. Older children in the Section 8 group again show large negative effects on court judgments. Our estimate suggests that using a Section 8 voucher lowers these debts by $\$ 456,73 \%$ lower than the control group average, but is only marginally significant at $p=0.14$. Younger children across both treatment groups and older children in the Experimental group otherwise do not show any significant estimates on court judgment amounts.

Column 5 reports the impact of MTO on overdue debts held by third party collection agencies. Overall we do not find statistically significant effects of MTO on the balance held in 3rd party collection agencies across any age or MTO treatment group, although our confidence intervals cannot reject either large negative or large positive effects. Note that although the estimated effects on individual components are not themselves significant, the estimate for the summary index can provide more power and detect significant effects within the domain as a whole. Within the older children Section 8 subgroup, for example, estimates on amounts past due, tax liens, and judgement amounts are nearly significant at the $10 \%$ level and estimated coefficients are of large magnitude. The overall delinquency index for older children within Section 8 families is thus negative and highly significant at the $p=0.01$ level, indicating overall lower delinquencies relative to the control group. Similarly, the overall delinquency index of younger children within the Experimental group is negative and significant at the 10 percent level. While not significant, estimated impacts of an Experimental voucher for younger children on tax liens and bills sent to third party collection agencies are particularly large and negative when compared to the control group mean. 


\section{E. Impacts of MTO on Payday Loan Usage}

Given the subprime credit scores of most of the MTO sample, MTO families may have turned to alternative lending options such as payday loans. Tables IV reports the effects of the MTO program on the outcomes underlying the payday indices in Table $\mathbb{1}$. We find reduced payday usage primarily across younger children within families that moved with Section 8 vouchers. We calculate negative impacts for adults and older children but effects are not statistically significant.

Column 2 reports the total amount held in payday loans each year. On average across all ages, MTO participants within the control group take out approximately $\$ 19$ in payday loans per year. Note that this is averaged over many people who take out $\$ 0$ in payday loans and some people who take out larger amounts ${ }^{13}$ Estimated impacts are negative and significant for younger children of Section 8 families. For younger children, the mean total payday amount in the control group is $\$ 22$. Younger children within families that took up a Section 8 voucher hold $\$ 16$ less in payday loans - a $72 \%$ decline in debt relative to the control group mean. Estimated impacts within the Experimental treatment group are negative across all subgroups, but not statistically significant. The estimated impact on payday amounts for adults within the Section 8 group are essentially equal to zero, and effects for older children are positive but not significantly different than 0 .

Columns 3 and 4 of Tables IV] break up the total payday amounts into internet and storefront. Payday loans were originally offered alongside check cashing storefront vendors, but have more recently expanded to offer online options as well. The amount borrowed across these types are both approximately $\$ 9$ on average (including many zeroes for non-users) for online and storefront within the MTO control group. Adults borrow slightly less online than younger children $(\$ 7$ versus $\$ 10)$, while older children within the control group borrow nearly twice the amount (\$17) online. Younger children within the control group also borrow more than adults from physical stores $(\$ 12$ $\mathrm{v} \$ 7)$, while older children of the control group borrow much less from physical stores $(\$ 2)$.

We again find the negative impacts on payday usage among younger children within Section 8 families, from both online and storefront lenders. The TOT estimates indicate that younger children within Section 8 families who used the voucher borrow $\$ 5.5$ less in online payday loans

\footnotetext{
${ }^{13}$ The size of a typical payday loan in our sample is $\$ 250$, although some users take out many loans within a single year. On average, those who use payday loans take out 2.8 loans per year. Summary statistics on payday and all other outcomes are available in the data appendix.
} 
on average than children within the control group, indicating they hold nearly $50 \%$ fewer debts in internet payday loans. Younger children within Section 8 families also borrow $\$ 10.7$ less in storefront payday loans, more than $60 \%$ relative to the control group mean. The reduction in usage of online payday loans is particularly interesting because online payday loans are essentially accessible from anywhere. This suggests that the reduction in payday loan usage is not due exclusively to increased costs associated with physically accessing brick-and-mortar payday loan stores, and could instead be driven by peer effects, marketing, information, or neighborhood social norms. Estimated impacts on storefront amounts for Section 8 younger children are also large in magnitude, indicating $80 \%$ less payday debt than the control group mean with $p<0.05$. Effects for adults, older children, and younger children within the Experimental group for both internet and storefront payday borrowing are not significantly different from zero.

The final component of our index measures the number of payday inquiries, or applications for payday loans both online and storefront. The control group applies for an average of 0.1 payday loans per year. Older children within Section 8 families show to make fewer payday loan applications, although the effect is not statistically significant. Other estimated impacts for all other age and treatment groups are also not significant for payday applications. Although Clarity covers a large percentage of sub-prime borrowers, and over 70 percent of MTO recipients were linked to the Clarity database, it is important to note that these data underestimate payday loan usage and inquiries. The Clarity data only contain information on payday loans and inquiries for lenders that use their underwriting services, so decreases in payday loan usage from lenders not included in the Clarity database would not be captured in our analysis.

\section{Channels of Neighborhood Impact}

In our main analysis, we find that moving to lower poverty neighborhoods has benefits for credit, delinquencies, and payday usage, but with differential impacts across age groups and treatment arms. In particular, we find that requiring families to move to the lowest poverty neighborhoods with the Experimental voucher increases credit scores and use of credit in adulthood among those randomized as young children, but does not improve outcomes for those randomized to the Experimental arm as adults and older children. In contrast, we find that allowing families to move to the 
neighborhood of their choice with Section 8 vouchers results in significant reductions in overdue debts and delinquencies for those randomized as adults and older children, while still modestly improving credit worthiness and usage in adulthood for those randomized as younger children. We thus pursue further exploratory analysis to understand the potential channels through which neighborhoods may have generated this pattern of results. While the nature of the experiment does not allow us to conclusively state which channels are the most important, we are able to explore patterns that are suggestive of certain mechanisms but not others.

\section{A. Direct Effects of Neighborhood through Credit Demand}

In Section [II, we identify channels through which neighborhoods can directly affect credit outcomes by altering participants demand for credit. We first explore peer effects, one of the most prominent mechanisms cited by the empirical literature within household finance. We could observe younger children in MTO families experience improved credit scores and and adults in Section 8 families reduce delinquencies through "positive" peer effect channels such as information diffusion or "mimicking" good peer behavior.

In order to examine this peer effect channel further, we first characterize the credit and delinquency outcomes of the neighbors of MTO participants. To do so, we obtain a random sample of a panel of 4 million individuals and use it to estimate average outcomes of residents within zip codes where MTO participants lived in between 2001 to 2017. Our MTO linked credit sample allows us to follow the zip code of residence of MTO participants over our sample period 14 We then merge each MTO participant with zip code characteristics derived from our random sample to calculate the credit characteristics of other zip code residents. This allows us to compare the outcomes of MTO participants to the outcomes of peer residents in the same zip code ${ }^{15}$

It is important to note that these variables characterize zip code characteristics of MTO participants many years after they received the MTO voucher. Differences in zip code characteristics across treatment arms therefore demonstrate the persistent and long-term impact of MTO voucher

\footnotetext{
${ }^{14}$ Zip code is the finest geographic level available on the credit report. Note that zip codes are a finer level of geography than used in other studies of peer effects, such as e.g. Brown et al. (2008) who use metropolitan statistical area.

${ }^{15}$ A small number of MTO participants live in zip codes for which too few people are observed in the 4 million Experian sample to calculate zip code level means. These individuals are excluded. This affects fewer than 8 percent of the observations.
} 
receipt on these neighborhood characteristics. Also note that because we use participants' zip codes from credit reports to define neighborhoods, these measures are the neighborhood characteristics of MTO participants as adults. Our estimates for MTO children therefore indicate the characteristics of neighborhood they chose to move to in adulthood.

Column 1 of Table $\mathrm{V}$ summarizes the average credit outcomes of peers within neighborhoods MTO participants moved to into one peer credit index. This index combines all the same underlying components we measure in Table $\mathrm{V}$ of MTO participants themselves: credit scores, credit limits, total balance, monthly payment, and credit availability. As noted in previous sections, it is important to remember that these variables are all equilibrium outcomes of credit market demand and supply. Thus finding that young children of the MTO participants look more like their peers could be consistent with a peer effect of "mimicking" or social information, but could also be consistent with lenders supplying greater credit access to the neighborhoods they move to. In the following section, we test more directly whether the supply channel moves through proximity to financial institutions.

The peer credit index thus describes the average equilibrium credit market outcomes of neighborhood residents within the zip codes MTO adults moved to after random assignment and MTO children moved to into adulthood $\sqrt{16}$ The positive and significant coefficients reported in Table $\mathrm{V}$ demonstrates that being randomized into the Experimental or Section 8 group led individuals to live in neighborhoods where a typical resident has higher creditworthiness and greater use of mainstream credit markets. We observe this increase on neighborhood credit quality for all age groups, with particularly large effects among those randomized to the Experimental group as young children and adults. We find suggestive evidence of improvements among those in the Experimental group who were randomized as older children, although the effect sizes are smaller and not statistically significant.

We further explore peer effects by evaluating more systematically whether the MTO experiment caused participants' credit outcomes to look more like their neighbors as well. To do this, we re-scale our estimates of $\beta_{1}$ and $\beta_{2}$ of the underlying credit components in Column 1 by the difference between the voucher recipients' neighbors and the control group for each outcome ${ }^{17}$

\footnotetext{
${ }^{16}$ Results on the underlying components for peers are providing in Appendix Tables A5 and A6

${ }^{17}$ More details on this re-scaling are found in the Appendix. This method is similar to that used in Finkelstein et al. (2016).
} 
Appendix Figures A3 and A4 plot the coefficient estimates of these re-scaled estimates, $\tilde{\beta}_{1}$ and $\tilde{\beta}_{2}$, with asterisks to indicate whether these estimates are statistically significantly different from zero ${ }^{18}$ The magnitude of the estimates can be interpreted as the percentage to which the voucher recipients have "converged" towards their neighbors' behavior, or if their behavior remains closer to the control group. For example, $\tilde{\beta}_{1}=1$ indicates that the recipients of the voucher now behave exactly like their neighbors; $\tilde{\beta}_{1}=0.50$ indicates that the recipients have converged 50 percent to the behavior of their new neighbors; and $\tilde{\beta}_{1}=0$ indicates that the recipients have not converged at all and behave exactly like the control group.

Figures A3 and A4 show that we only find consistent evidence of convergence towards neighbors' behavior among those who were youngest (under age 13) at the time of random assignment in both the Experimental and Section 8 treatment groups. We find that among credit use and creditworthiness outcomes, MTO participants converge towards their peers across all components in the both treatment groups. In general, the size of the convergence is no more than 5 percent-that is, the younger children in MTO treatment groups move no more than approximately 5 percent of the way towards their new peers. This effect may seem small, but it is important to bear in mind that there is tremendous inequality between MTO participants-who were all residents of public housing projects with low levels of educational attainment in single parent (mother) families-and a typical individual living in a low poverty neighborhood. Making up even 5 percent of this gap can represent meaningful improvements given the low baseline rates of engagement with formal credit markets. Nonetheless it is important to keep in mind that although they experienced improvements in credit-worthiness and greater credit use, younger children in both treatment groups still remain very different from the average resident of the low poverty neighborhoods they inhabit. At the same time, we find no consistent evidence of convergence for those randomized to the Experimental group as older children or adults. If anything, we find that these groups behaved less like their new neighbors than the control group. This lack of convergence again suggests that if peer effects existed at all for these groups, that they were dominated by other factors.

In column 2 of Table $\mathrm{V}$ we examine the average delinquency behavior of peers within neighborhoods MTO participants moved to into adulthood. We do not find that MTO participants live in neighborhoods with any lower average delinquency behavior than the neighborhoods experienced

\footnotetext{
${ }^{18}$ We show significance levels, rather than confidence intervals, in order to keep the y-axis scale readable.
} 
by the control group, and our confidence intervals can rule out all but small improvements. Although we see no improvements overall, Appendix Table A6 shows that the neighbors of Section 8 adults did have significantly lower amounts of debt 30 days past due and in collections, but higher amounts of debt due in judgements. Thus when we examine how much Section 8 adults converge their delinquency behavior to their neighbors, we find estimates that are close to 0 - because their MTO neighborhood peers reduced their delinquencies no more than their control group counterparts - or significantly greater than 1 - because they reduced their debts significantly more than both their control group and their neighborhood peers 19 Thus it appears there is some evidence suggesting that Section 8 adults reduced their past due debt due to peer effects, although the pattern is not as strong as observed for those randomized as young children.

It is important to highlight that we do not find the same benefits to delinquencies for adults in the Experimental treatment group that we find for those in the Section 8 voucher group. Thus, this result suggests that the type of voucher plays an important role in the mechanism through which the MTO program impacted credit behaviors. The MTO program required families in the Experimental arm to move to neighborhoods of very low poverty rates, while Section 8 families could utilize their vouchers with no restriction ${ }^{20}$ Moving to a very low poverty neighborhood could add higher living costs while simultaneously disrupting informal peer lending networks. Thus in Column 3 of Table $\mathrm{V}$ we examine this channel by comparing the average level of peer credit card spending across treatment arms as a proxy for neighborhood cost of living 21 We find that while adults in both treatment arms live in zip codes where peers have higher spending on average relative to the control group, and adults in the Experimental arm live in neighborhoods with significantly higher average expenditures than those in the Section 8 group 22 Our estimates show that using a Section 8 voucher causes participants to live in zip codes in adulthood where average credit

\footnotetext{
${ }^{19}$ Note that nothing restricts the convergence estimate to be inside of the $(0,1)$ interval. An estimate significantly greater than 1 indicates that while their neighborhood peers have lower past due debt, for example than the control group, MTO adults reduced their delinquency even more so than their neighbors - reducing delinquency behavior far past their neighborhood peers relative to the control group. Second, if they move to neighborhoods where residents are largely similar to the control group, $\Delta y$ will be close to zero, which would indicate that there are no peer effects because, essentially, there has been no "treatment" - the experimental arm is not experiencing "new" peers.

${ }^{20}$ Follow up studies document that families in the Experimental arm moved - and on average stayed - in locations that were further from their original locations, while Section 8 families moved to better neighborhoods that were closer.

${ }^{21}$ Gross et al. (2018) develop a model showing the relationship between credit card balances and consumption. In this work, the authors show that in many empirical settings credit card balances are a good measure of consumption, particularly in low income populations with low levels of liquid savings such as the MTO participants.

${ }^{22}$ Note that credit card expenditures are not themselves a component of the credit index reported in Column 1.
} 
card balances are approximately $\$ 182$ higher relative to the control. Adults using an Experimental voucher move to zip codes where average balance are $\$ 380$ higher, more than double the increase in peer expenditures of those who moved using a Section 8 voucher. We find a similar pattern across children, although a smaller magnitude (\$195) among those randomized as older children. Given that Chetty et al. (2016) find that treated MTO participants live in neighborhoods with lower poverty rates and higher average incomes as adults, it is perhaps unsurprising that these participants also live in neighborhoods where residents tend to have higher spending. As such, this result is not entirely novel. However, because we observe participants over different years in adulthood, and because expenditure and income can vary if savings rates differ across neighborhoods, we provide the results in Table $\mathrm{V}$ to re-establish this fact for our sample.

In column 4 of Table V we also further explore the neighborhood credit utilization rates - or the ratio of balance to available credit - as a further test of higher living costs in MTO neighborhoods. If residents of MTO neighborhoods are spending more, utilization rates provide a measure of how constrained this spending is within their credit availability. Interestingly, we find that only families who moved with the Section 8 voucher live in neighborhoods with lower utilization relative to the control group. Although this estimate is only statistically significant among those randomized as young children, the point estimate is consistently negative for the Section 8 group, but positive for those in the Experimental group who moved as older children or adults. Thus, adults who moved with the Experimental voucher may not only faced higher living costs but also pressure to "keep up with the Joneses" given that their neighbors were earning and spending higher amounts than the MTO participants. Given the null estimates on income from prior studies, we know adults in both MTO treatment groups did not have any additional income to support their families. Thus if moving to a low poverty neighborhood required additional costs and investment in their children, adults who were required to move to the lowest poverty neighborhoods in the Experimental may have not had the additional resources to pay off past debt as adults in the Section 8 group.

\section{B. Direct Effects of Neighborhood through Credit Supply}

As described in Section II] neighborhood proximity to lending institutions has also been proposed as an important mechanism that drives the relationship between neighborhoods and credit market behavior. To examine this relationship, we assemble data from the Census Business Pat- 
terns on the number of banks and lending institutions (NAICS 522110) and number of payday loan stores (NAICS 522291 and 522390, following Bhutto (2014)). We then calculate the number of banking and payday loan institutions within each zip code MTO participants move to from 2001 to 2017. If physical proximity to payday loan stores reduces payday borrowing, we would expect individuals who moved to better neighborhoods to reside in areas with fewer payday loans stores relative to those who did not move with the experiment. In the same way if neighborhoods impact credit outcomes through proximity to traditional banking institutions, we would find treatment participants to move to neighborhoods with a greater number of banking institutions relative to the control group ${ }^{23}$ The two separate treatment groups of the MTO experiment may feel different impacts of distance from informal lending networks. Families who moved with the Experimental treatment group were required to move to neighborhoods of very low poverty groups, while those assigned to the Section 8 treatment group were allowed to move to any neighborhood of their choosing. Thus, families within the Section 8 group may have been able choose locations that allowed them to maintain informal lending networks more than those assigned the Experimental vouchers. Follow up MTO studies find that Section 8 treatment households moved to neighborhoods with higher average poverty rates than Experimental families, of approximately 27.8 percent versus 10.8 percent respectively.

Columns 5 and 6 of Tables $\mathrm{V}$ examine whether MTO participants moved to zip codes with fewer payday loan stores or greater access to physical banks. Our estimates indicate that only younger children of Section 8 families moved to zip codes with statistically significantly fewer payday establishments; using a Section 8 voucher lowered the number of payday low stores in the zip code in adulthood by 0.16 stores, or about 8 percent among this group. This reduction in neighborhood payday establishments is significantly different from the effect observed in the Experimental group at the $5 \%$ level (as denoted by the $\diamond$ symbol). In addition to being the only group for which we observe reductions in payday store access, the youngest Section 8 voucher recipients are also the only subgroup in which we observe reductions in payday loan use. Taken together, these results suggest that the physical presence of payday loan stores in a neighborhood may be an important mechanism by which neighborhoods affect subprime borrowing behavior. Although we find no

\footnotetext{
${ }^{23}$ Recall that we examine the number of financial intermediaries for participants in adulthood. It is important to note that even in the absence of differential proximity to financial intermediaries in adulthood, participants randomized as children may have still experienced different exposure to financial intermediaries in childhood.
} 
statistically significant change in the number of banks in neighborhoods relative to the control group, we do observe that those randomized at young ages in the Experimental group live in neighborhoods with more banks than the Section 8 group, further suggesting that the benefits to credit access we observe for younger children in the Experimental group may be in part due to physical availability of banks within a zip code. While we do not detect that the number of banks differs significantly between the treatment arms and the control group, we note that our confidence intervals do not allow us to reject that there may have been meaningful effects.

Finally as we note in the previous section, even if we do not find differences in the number of physical institutions, this does not rule out that MTO participants may have moved to zip codes where lenders provided greater credit access in those neighborhoods. Lenders may for some reason been more willing to lend to MTO participants if participants appeared more likely to repay debts after moving to an low poverty neighborhood. While we do not find that those randomized as young children to the Experimental group had fewer delinquencies, other work by Chetty et al. (2016) shows that they had higher incomes in adulthood, which may have increased creditors' willingness to lend. We explore this mechanism in the next sub-section.

\section{Indirect Effects of Neighborhood through Income}

Finally, we explore indirect effects moving to MTO neighborhoods could have on credit outcomes through income. Results from Chetty et al. (2016) show that only younger children who were randomized into the experimental voucher group experienced higher incomes in adulthood, and that the incomes of those randomized as adults or older children were unaffected. We also find the largest impact of the vouchers on credit score and use of credit in this group. Increases in income may alter both the demand for credit, if higher income consumers tend to apply for more credit, and the supply of credit, if lenders are more willing to provide credit to those with higher incomes. Recent work in empirical household finance allows us to provide a "back of the envelope" calculation as to how much of the observed increase in credit score among the Experimental group is due to the increase in income and how much might be attributable to neighborhood effects operating through a non-income channel.

Chetty et al. (2016) find that young children who moved with Experimental vouchers earn approximately $\$ 3,447$ more annually than young children who stayed within the control group 
respectively. Cookson et al. (2019) estimate a $\$ 5000$ to $\$ 20,0000$ increase in wealth increases credit scores for subprime, low income borrowers by 4 to 7 points, which would attribute between $36 \%$ and $63 \%$ of our 11 point estimate to improved income. We can also conduct a similar calculation using work that relies on the random assignment of bankruptcy petitioners to judges to conduct a similar analysis. Dobbie and Song (2015) show that Chapter 13 bankruptcy protection increases annual income by $\$ 5,562$ on average and Dobbie et al. (2017) show that it increases credit scores by 17 points. Dobbie et al. (2017) also show that half of the effect of bankruptcy protection on financial outcomes dissipates after the actual period of bankruptcy protection ends, suggesting that the "indirect" impact of bankruptcy on credit score is an increase of approximately 8.5 points ${ }^{24}$ Under the (strong) assumption that the credit score increase is driven primarily by the increase in earnings, we would therefore ascribe at most a 1.5 point increase to every $\$ 1000$ in additional annual earnings $\left(\frac{8.5}{\$ 5,562} \times \$ 1,000\right)$. Since income increased by about $\$ 3,447$ in the experimental group, we might expect a 5.2 point increase in credit score resulting directly from the increase in income experienced by those randomized to the Experimental group; again, this suggests that about half of the effect of neighborhoods on credit score may be due to the income channel, with the remaining effect likely due to more direct neighborhood mechanisms such as exposure to financial institutions or peer effects.

\section{Summary of Discussion}

While neighborhoods could affect a myriad of secondary outcomes, we identify 4 potential mechanisms that appear to be well-established within the empirical literature on household finance. Moving to a lower poverty neighborhood could improve delinquency or liquidity if adults benefit from (1) a "social information" peer effect or (2) a local supply effect (i.e. physical and proximate access to banking institutions and increased distance to payday loan stores or higher willingness of lenders to supply credit). At the same time, adults might experience increases in delinquency if they are subjected to (3) a "Keeping Up with the Joneses" peer effect or (4) a disruption cost of moving away from local support networks, which it is reasonable to assume are larger for adults in

\footnotetext{
${ }^{24}$ We calculate that roughly half of the overall effect is due to the "indirect" effects of bankruptcy by comparing the effect observed in years 6-10, after the bankruptcy protection period has ended, to the effect from the pooled two-stage least squares estimator reported in the working paper version of Dobbie et al. (2017). Since credit score is not reported separately for years 1-5 and years 6-10, we assume it follows the same pattern as other financial outcomes that are reported over these time intervals.
} 
the Experimental group given the experimental design.

From previous research, we know that adults who participated in MTO did not experience any increase in earnings or change in employment outcomes. Indeed, despite collecting a wide variety of survey and administrative outcomes, MTO follow up evaluations detected essentially no impact of the program on income or labor market outcomes for adults (Orr et al., 2003; Kling et al., 2007, Sanbonmatsu and Lindau, 2011; Chetty et al., 2016). Our results suggest that the improvements in delinquency behavior for Section 8 adults and older children therefore reflect the direct impact of neighborhoods on credit behavior.

The fact that we do not observe similar improvements among the Experimental adults and older children suggest that the negative effects of moving to a higher income neighborhood described in (3) and (4) must be dominating any positive effects of (1) and (2) for this group. Furthermore, the experimental design makes it likely that the benefits of (1) and (2) are at least as large for the Experimental group as for the Section 8 adults. So, the fact that we find improvements among Section 8 adults in delinquency outcomes suggests that, on net, the direct neighborhood effects of moving out of a public housing facility and into a neighborhood of one's choosing are positive, but there is no evidence of benefits if the voucher recipient is forced to move to a low poverty neighborhood where living costs and disruption costs are higher.

This finding has important policy implications. Our results show that adults and older children are better off if they are permitted to choose their own neighborhoods, and this improvement reflects a direct effect of neighborhoods on outcomes. This finding is relevant particularly in light of recent, high profile work encouraging local housing authorities to incentivize families to move to pre-selected neighborhoods (Bergman et al. (2019)).

In contrast, those who move early in childhood face a very different set of costs and benefits. While the negative direct impacts of (3) and (4) may still be present, the positive direct effects of (1) and (2) may be larger, since children have a longer period over which they can benefit from peer effects and proximity to credit institutions. Indeed, Brown et al. (2019) find that exposure to financial institutions early in life can have long-run implications on household finance outcomes.

In addition to these direct impacts of neighborhoods, those who were children during MTO also may experience better financial outcomes due to the indirect impact of neighborhood-that is, improved incomes, which might in turn improve credit market behavior and outcomes. Naturally, 
the presence of both direct and indirect effects makes mechanisms difficult to untangle. Here, we benefit from the rapidly developing literature in household finance that measures how changes in income affect credit market outcomes using a variety of quasi-experimental methods. Backof-the-envelope calculations suggest that higher income accounts for about half of the impact of neighborhood on credit scores. This suggests the additional impact of neighborhood on credit likely works through direct channels such as peer effects and nearby access to financial institutions.

\section{Additional Results and Heterogeneity Analysis}

In addition to our main analysis, we also undertake several supplemental analyses to further explore the effects of neighborhoods across different groups and outcomes. Because we consider these results exploratory, we do not apply the multiple hypothesis adjustment to the inference conducted in these analyses.

First, we examine the impact of MTO on homeownership, mortgage delinquency, and bankruptcy ${ }^{25}$ These outcomes have garnered particular interest in the literature surrounding peer effects given the hypothesized relationship between social stigma and bankruptcy and foreclosure (e.g., Gross and Souleles (2002), Cohen-Cole and Duygan-Bump (2008)) as well as the role of neighbors' income and consumption in increasing the likelihood of bankruptcies (Agarwal et al. 2019).

The results are reported in Table A7. We observe that using a voucher at a young age results in participants being more likely to have a mortgage in adulthood. We do not find statistically significant effects on the likelihood of being delinquent on the mortgage or of declaring bankruptcy, although our confidence intervals cannot rule out meaningfully sized effects.

Second, we undertake further heterogeneity analysis based on the age of random assignment. We explore the impact observed in the credit records at age 24 and older of those randomly assigned under the age of 10, at ages 10-12, 13-15 and 16-18. These results are reported in Appendix Figure A3. We confirm that the strongest impacts of neighborhood on credit-worthiness and usage emerge for those who were youngest when random assignment occurred-particularly those under age 10 (for the Experimental and Section 8 group) and those age 10-12 (for the Experimental group). Our analysis of delinquency outcomes is significantly noisier, making it difficult to draw strong

\footnotetext{
${ }^{25}$ Note that we do not have foreclosures as a variable in our dataset.
} 
conclusions, but we note that large negative coefficients are observed in both the Experimental and Section 8 groups for those randomized at the youngest ages.

Third, we explore how the effects of MTO change as participants age. Appendix Figure A4 shows the effect of moving to a lower income neighborhood at ages 18-21, age 22-24, age 25-27 and age 28 and older. The blue line shows the impact of MTO at these ages for those who were randomized at a young age (under 13) and the green line shows the impact for those who were randomized at an older age (13-17). We see that the effects appear to grow over time for those in the Experimental group who were randomized at young ages, suggesting that the impact of MTO may be become larger as they move towards their prime earning years, consistent with impacts on income found in Chetty et al. (2016). Among the Section 8 group, we see that the impact of MTO on measures related to delinquency is larger for those in older age ranges, although the pattern is less clear for measures related to use of credit.

\section{Conclusion}

This paper examines the impact of better neighborhood on credit and subprime credit decisions of low-income households within the Moving to Opportunity Experiment. We find that neighborhood environment has significant direct impacts on credit outcomes, outside of channels of income. We find that the youngest children in the MTO experimental group experienced the greatest benefits in terms of credit-worthiness and use of credit. Young children of families in the experimental arm were required to move to the lowest poverty neighborhoods ( $<10$ percent) and received the longest exposure to low poverty neighborhoods. We find that these children have higher credit limits and credit scores in adulthood relative to the control group, along with greater active use of credit and revolving credit available. These results are consistent with credit improvements through income increases documented by Chetty et al. (2016). Back-of-the-envelope calculations suggest that higher income accounts for about half of the impact of neighborhood on credit scores of younger children, and the additional impact of neighborhood on credit likely works through alternative direct channels such as peer effects.

In contrast to prior MTO results, however, we document positive impacts for adults on other dimensions. We find adults and older children within the Section 8 voucher group experience 
significant improvements in delinquencies and overdue debts. Interestingly, we do not find the same benefits to delinquencies for adults in the Experimental treatment group. Our analysis suggests that adults within the Experimental group moved to neighborhoods with higher average expenditures, and thus may have been unable to repay debts as easily as those given an unrestricted choice of neighborhood. Requiring families to move to low poverty neighborhoods could have also reduced access to informal support systems and avenues of borrowing, such as from family and friends. Our results suggest that policies that aim to improve neighborhood environments may also consider providing flexibility in neighborhood choice in order to retain informal support networks already in place or provide additional assistance to keep up with increased costs of living.

We also note that in most cases, the magnitude of the effects we uncover are large and economically meaningful when compared to the baseline mean in the control group, but small when compared to the disparities observed between MTO group and the overall population. For example, the $\$ 821$ increase in average credit card limits experienced by those randomized to the Experimental arm as young children is more than $60 \%$ higher when compared to their control group counterparts. However, it is trivial compared to the average credit card limit in the population, which is over $\$ 20,000$ (Gross et al., 2018). This implies that while improving neighborhood quality makes progress in alleviating the credit constraints of low income borrowers, it will likely not make a meaningful impact on the observed disparities between rich and poor.

Our results highlight the policy concern that many local housing authorities still face in relocating families to low poverty neighborhoods. While many acknowledge the benefits of a better neighborhoods, local authorities still face challenges on how to help families maintain economic self-sufficiency once in a higher cost neighborhood. In our conversations with local housing authorities, even if voucher recipients are able to find housing that accepts Section 8 vouchers in lower poverty neighborhoods, families face challenges in building the credit to qualify for or remain in neighborhoods with low poverty rates. Since the rental subsidy of a Section 8 voucher is set by metropolitan area, the amount of the subsidy is of lower value in a higher cost zipcode. The null effects we find on credit scores and credit limits for adults, reveal that it is still very difficult to build credit with improved improved delinquency behaviors alone. Thus, our findings highlight that while moving to better neighborhoods can have important intergenerational benefits for credit behavior, assisting families in building and maintaining the credit to remain these neighborhoods 
remains an important policy concern. 
Table I Effect of MTO on Credit Outcomes: Summary

\begin{tabular}{|c|c|c|c|c|c|c|c|c|}
\hline & \multicolumn{2}{|c|}{ All Participants } & \multicolumn{2}{|c|}{ Adults } & \multicolumn{2}{|c|}{ Older Children } & \multicolumn{2}{|c|}{ Young Children } \\
\hline & $\begin{array}{c}\operatorname{Exp} \\
(1) \\
\end{array}$ & $\begin{array}{c}\text { Sec } 8 \\
(2) \\
\end{array}$ & $\begin{array}{c}\text { Exp } \\
(3) \\
\end{array}$ & $\begin{array}{c}\text { Sec } 8 \\
(4)\end{array}$ & $\begin{array}{c}\operatorname{Exp} \\
(5)\end{array}$ & $\begin{array}{c}\text { Sec } 8 \\
(6)\end{array}$ & $\begin{array}{c}\operatorname{Exp} \\
(7) \\
\end{array}$ & $\begin{array}{c}\text { Sec } 8 \\
(8)\end{array}$ \\
\hline Credit Index & $\begin{array}{c}0.051^{*} \\
(0.030)\end{array}$ & $\begin{array}{c}0.022 \\
(0.020)\end{array}$ & $\begin{array}{c}0.035 \\
(0.051)\end{array}$ & $\begin{array}{c}0.003 \\
(0.012)\end{array}$ & $\begin{array}{c}-0.047^{\dagger} \\
(0.043)\end{array}$ & $\begin{array}{c}-0.0138 \\
(0.036)\end{array}$ & $\begin{array}{c}0.082^{* * *} \\
(0.025)\end{array}$ & $\begin{array}{c}0.0348^{*} \\
(0.019)\end{array}$ \\
\hline Delinquency Index & $\begin{array}{c}-0.008 \\
(0.012)\end{array}$ & $\begin{array}{c}-0.025^{* * *} \\
(0.006)\end{array}$ & $\begin{array}{c}0.008 \\
(0.021)\end{array}$ & $\begin{array}{c}-0.033^{* * *} \\
(0.011)\end{array}$ & $\begin{array}{c}-0.010 \\
(0.018)\end{array}$ & $\begin{array}{c}-0.042^{* * *} \\
(0.015)\end{array}$ & $\begin{array}{c}-0.035^{* \diamond} \\
(0.018)\end{array}$ & $\begin{array}{l}-0.009 \\
(0.013)\end{array}$ \\
\hline Payday Index & $\begin{array}{c}-0.003 \\
(0.004)\end{array}$ & $\begin{array}{c}-0.009^{* *} \\
(0.005)\end{array}$ & $\begin{array}{c}-0.009 \\
(0.023)\end{array}$ & $\begin{array}{l}-0.008 \\
(0.017)\end{array}$ & $\begin{array}{c}-0.048 \\
(0.033)\end{array}$ & $\begin{array}{l}-0.001 \\
(0.048)\end{array}$ & $\begin{array}{c}0.001^{\diamond} \\
(0.022)\end{array}$ & $\begin{array}{c}-0.033^{* * *} \\
(0.011)\end{array}$ \\
\hline Observations & 136,203 & & 63,410 & & 25,942 & & 46,851 & \\
\hline
\end{tabular}

Note: This table reports the difference in means for recipients of Experimental or Section 8 vouchers relative to the control group. The mean of the outcome variable in the control group is reported at the bottom of each respective column. Per comparison p-values are reported in parentheses, and family-wise error rate adjusted p-values are reported in square brackets under each estimate. See text for more details. The symbol $\dagger$ indicates that the estimate differs significantly from the estimate among those randomized as young children. The symbol $\diamond$ indicates that the estimate differs significantly from the estimate of the effect of the Section 8 treatment arm. Significance levels: $*=10$ percent; $* *=5$ percent; $* * *=1$ percent 
Table II Effect of MTO on Credit Outcomes, Adults and Children

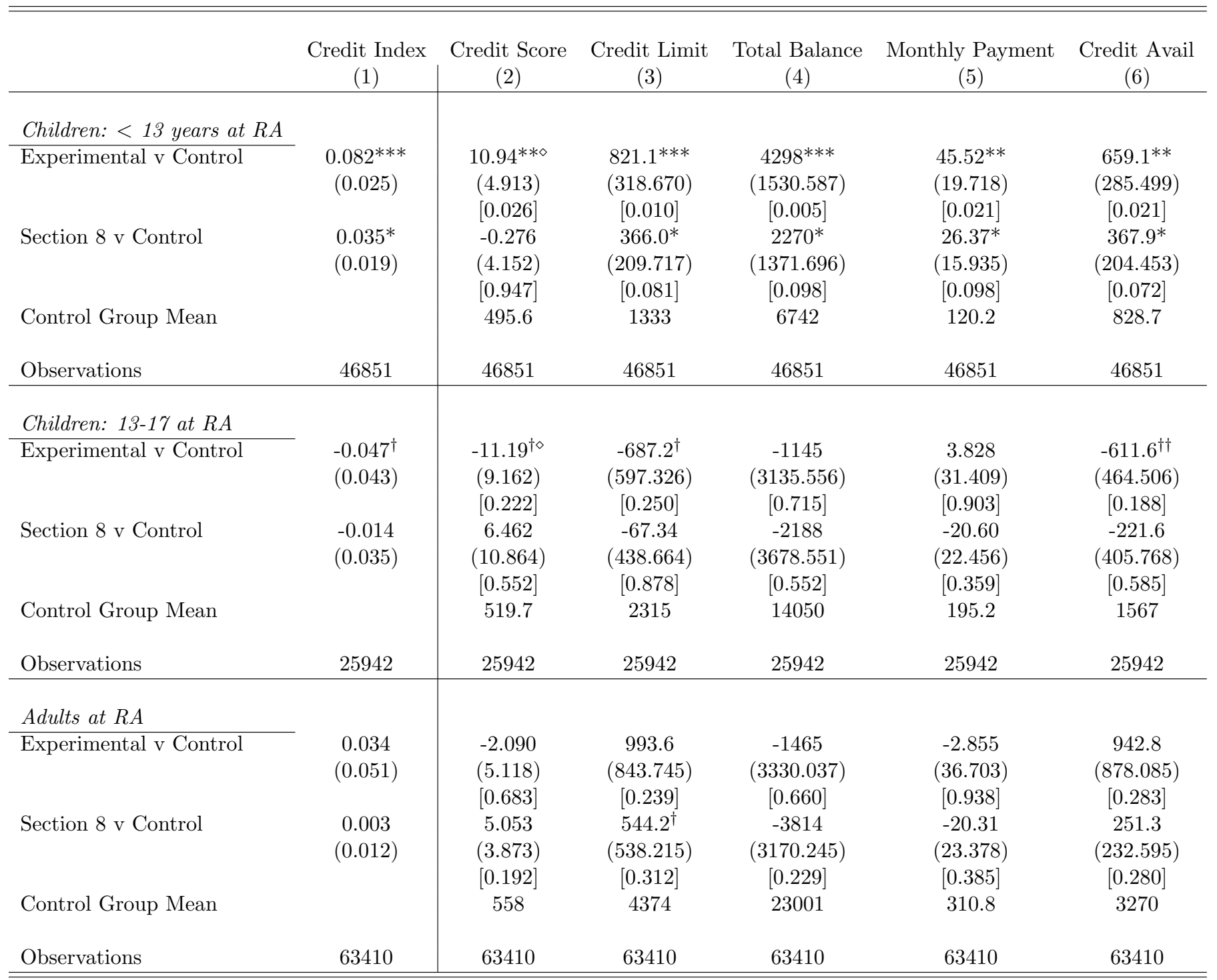

Note: This table reports the difference in means for recipients of Experimental or Section 8 vouchers relative to the control group. The mean of the outcome variable in the control group is reported at the bottom of each respective column. Per comparison p-values are reported in parentheses, and family-wise error rate adjusted p-values are reported in square brackets under each estimate. See text for more details. The symbol $\dagger$ indicates that the estimate differs significantly from the estimate among those randomized as young children. The symbol $\diamond$ indicates that the estimate differs significantly from the estimate of the effect of the Section 8 treatment arm. Significance levels: $*=10$ percent; $* *=5$ percent; $* * *=1$ percent 
Table III Effect of MTO on Delinquency Outcomes, Adults and Children

\begin{tabular}{|c|c|c|c|c|c|}
\hline & $\begin{array}{l}\text { Delinquency Index } \\
\text { (1) }\end{array}$ & $\begin{array}{c}30 \text { Days Past Due } \\
(2)\end{array}$ & $\begin{array}{c}\text { Tax Liens } \\
(3)\end{array}$ & $\begin{array}{c}\text { Judgment Amount } \\
(4)\end{array}$ & $\begin{array}{c}\text { Collections } \\
(5)\end{array}$ \\
\hline \multicolumn{6}{|c|}{ Panel A: Age $<13$ years at $R A$} \\
\hline \multirow[t]{2}{*}{ Experimental v Control } & $\begin{array}{c}-0.035^{* \diamond} \\
(0.018)\end{array}$ & $\begin{array}{c}67.13 \\
(88.663)\end{array}$ & $\begin{array}{l}-241.5^{\diamond \diamond} \\
(243.328)\end{array}$ & $\begin{array}{c}-12.08 \\
(123.367)\end{array}$ & $\begin{array}{c}-425.6 \\
(428.822)\end{array}$ \\
\hline & & {$[0.449]$} & [0.321] & {$[0.922]$} & {$[0.321]$} \\
\hline \multirow[t]{3}{*}{ Section 8 v Control } & -0.009 & 176.9 & -128.4 & 104.5 & -246.5 \\
\hline & $(0.013)$ & $(245.942)$ & $(178.513)$ & $(173.503)$ & $(216.989)$ \\
\hline & & {$[0.472]$} & {$[0.472]$} & {$[0.547]$} & {$[0.256]$} \\
\hline Control Group Mean & & 447.5 & 143.8 & 216.5 & 1775 \\
\hline Observations & 46851 & 46851 & 46851 & 42654 & 46851 \\
\hline \multicolumn{6}{|c|}{ Panel B: Ages $13-17$ years at RA } \\
\hline \multirow[t]{3}{*}{ Experimental v Control } & -0.010 & -123.5 & -52.40 & -208.3 & 142.9 \\
\hline & $(0.018)$ & $(296.461)$ & $(82.629)$ & $(752.730)$ & $(516.395)$ \\
\hline & & {$[0.677]$} & {$[0.526]$} & {$[0.782]$} & {$[0.782]$} \\
\hline \multirow[t]{3}{*}{ Section 8 v Control } & $-0.042^{* * *}$ & -399.0 & -42.90 & $-456.9^{\dagger}$ & -231.9 \\
\hline & $(0.015)$ & $(305.786)$ & (29.432) & $(314.238)$ & (285.699) \\
\hline & & {$[0.192]$} & {$[0.145]^{\prime}$} & {$[0.146]$} & {$[0.417]$} \\
\hline \multicolumn{2}{|l|}{ Control Group Mean } & 981.9 & 105.4 & 625.1 & 2028 \\
\hline Observations & 25942 & 25942 & 25942 & 18206 & 25942 \\
\hline \multicolumn{6}{|l|}{ Panel C: Adults at RA } \\
\hline \multirow[t]{3}{*}{ Experimental v Control } & 0.008 & -177.9 & 165.9 & $-400.5^{\dagger}$ & $224.2^{\dagger}$ \\
\hline & $(0.021)$ & $(253.589)$ & $(131.748)$ & $(417.971)$ & $(244.911)$ \\
\hline & & {$[0.483]$} & {$[0.208]$} & {$[0.338]$} & {$[0.360]$} \\
\hline \multirow[t]{3}{*}{ Section 8 v Control } & $-0.033^{* * *}$ & $-333.4^{* * \dagger}$ & $-101.0^{*}$ & $-279.5^{* \dagger}$ & 0.472 \\
\hline & $(0.011)$ & $(149.724)$ & $(55.931)$ & $(153.677)$ & $(94.146)$ \\
\hline & & {$[0.026]$} & {$[0.071]$} & {$[0.069]$} & {$[0.996]$} \\
\hline Control Group Mean & & 944.4 & 151.9 & 671.4 & 1915 \\
\hline Observations & 63410 & 63410 & 63410 & 41661 & 63410 \\
\hline
\end{tabular}

Note: This table reports the difference in means for recipients of Experimental or Section 8 vouchers relative to the control group. The mean of the outcome variable in the control group is reported at the bottom of each respective column. Per comparison p-values are reported in parentheses, and family-wise error rate adjusted p-values are reported in square brackets under each estimate. See text for more details. The symbol $\dagger$ indicates that the estimate differs significantly from the estimate among those randomized as young children. The symbol $\diamond$ indicates that the estimate differs significantly from the estimate of the effect of the Section 8 treatment arm. Significance levels: $*=10$ percent; $* *=5$ percent; $* * *=1$ percent 
Table IV Effect of MTO on Payday Outcomes, Adults and Children

\begin{tabular}{|c|c|c|c|c|c|}
\hline & $\begin{array}{c}\text { Payday Index } \\
(1)\end{array}$ & $\begin{array}{c}\text { Payday Amt } \\
(2)\end{array}$ & $\begin{array}{c}\text { Internet Amt } \\
(3)\end{array}$ & $\begin{array}{c}\text { Storefront Amt } \\
(4)\end{array}$ & $\begin{array}{c}\text { Payday Inquiries } \\
(5)\end{array}$ \\
\hline \multicolumn{6}{|c|}{ Children: $<13$ years at $R A$} \\
\hline \multirow[t]{3}{*}{ Experimental v Control } & $0.001^{\diamond}$ & -3.306 & 2.279 & -5.585 & 0.0191 \\
\hline & $(0.022)$ & $(9.053)$ & $(4.506)$ & $(14.648)$ & $(0.026)$ \\
\hline & & {$[0.715]$} & {$[0.613]$} & {$[0.703]$} & {$[0.455]$} \\
\hline \multirow[t]{3}{*}{ Section 8 v Control } & $-0.033^{* * *}$ & $-16.17 * * * \dagger$ & $-5.473^{* *}$ & $-10.69^{* *}$ & 0.00281 \\
\hline & $(0.011)$ & $(6.095)$ & $(2.271)$ & $(5.230)$ & $(0.014)$ \\
\hline & & {$[0.008]$} & {$[0.016]$} & {$[0.041]$} & {$[0.846]$} \\
\hline Control Group Mean & & 22.11 & 9.946 & 12.17 & 0.0857 \\
\hline Observations & 23204 & 23204 & 23204 & 23204 & 23204 \\
\hline \multicolumn{6}{|c|}{ Children: $13-17$ years at $R A$} \\
\hline \multirow[t]{3}{*}{ Experimental v Control } & -0.048 & -12.91 & $-17.62^{*}$ & 4.713 & -0.0357 \\
\hline & $(0.126)$ & $(75.368)$ & $(10.679)$ & $(13.346)$ & $(2.589))$ \\
\hline & & {$[0.525]$} & {$[0.152]$} & {$[0.683]$} & {$[0.313]$} \\
\hline \multirow[t]{3}{*}{ Section 8 v Control } & -0.001 & 9.231 & -4.570 & $13.80^{\dagger}$ & -0.0509 \\
\hline & $(0.001)$ & $(368.210)$ & $(31.321)$ & $(62.772)$ & $(0.349)$ \\
\hline & & {$[0.553]$} & {$[0.765]$} & {$[0.281]$} & {$[0.265]$} \\
\hline Control Group Mean & & 19.93 & 17.13 & 2.803 & 0.146 \\
\hline Observations & 7716 & 7716 & 7716 & 7716 & 7716 \\
\hline \multicolumn{6}{|l|}{ Adults: $18+$ at $R A$} \\
\hline \multirow[t]{3}{*}{ Experimental v Control } & -0.009 & -1.723 & -5.636 & 3.913 & -0.00129 \\
\hline & $(0.006)$ & $(2.710)$ & $(3.934)$ & $(9.581)$ & $(0.001)$ \\
\hline & & {$[0.864]$} & {$[0.099]$} & {$[0.724]$} & {$[0.989]$} \\
\hline \multirow[t]{3}{*}{ Section $8 \mathrm{v}$ Control } & -0.008 & -0.000654 & -1.360 & 1.359 & -0.0285 \\
\hline & $(0.328)$ & $(0.001)$ & $(4.549)$ & $(1.260)$ & $(0.026)$ \\
\hline & & {$[0.989]$} & {$[0.884]$} & {$[0.826]$} & {$[0.884]$} \\
\hline Control Group Mean & & 14.58 & 7.077 & 7.503 & 0.105 \\
\hline Observations & 17628 & 17628 & 17628 & 17628 & 17628 \\
\hline
\end{tabular}

Note: This table reports the difference in means for recipients of Experimental or Section 8 vouchers relative to the control group. The mean of the outcome variable in the control group is reported at the bottom of each respective column. Per comparison p-values are reported in parentheses, and family-wise error rate adjusted p-values are reported in square brackets under each estimate. See text for more details. The symbol $\dagger$ indicates that the estimate differs significantly from the estimate among those randomized as young children. The symbol $\diamond$ indicates that the estimate differs significantly from the estimate of the effect of the Section 8 treatment arm. Significance levels: $*=10$ percent; $* *=5$ percent; $* * *=1$ percent 
Table V Exploring Direct Channels of Neighborhood Impact

\begin{tabular}{|c|c|c|c|c|c|c|}
\hline & \multicolumn{2}{|c|}{ Peer Index } & \multicolumn{2}{|c|}{ Cost of Living } & \multicolumn{2}{|c|}{ Credit Supply } \\
\hline & $\begin{array}{l}\text { Credit } \\
\text { (1) }\end{array}$ & $\begin{array}{c}\text { Delinquency } \\
(2)\end{array}$ & $\begin{array}{c}\text { CC Spending } \\
(3)\end{array}$ & $\begin{array}{c}\text { Utilization } \\
(4)\end{array}$ & $\begin{array}{c}\text { Payday Stores } \\
(5)\end{array}$ & $\begin{array}{c}\text { Banks } \\
(6)\end{array}$ \\
\hline \multicolumn{7}{|c|}{ Children: Age $<13$ years at $R A$} \\
\hline \multirow[t]{3}{*}{ Experimental v Control } & $0.281^{* * * \diamond \diamond}$ & $0.00349^{\diamond}$ & $425.3^{* * * \diamond}$ & -0.385 & $0.0142^{\diamond \diamond}$ & $0.38^{\diamond \diamond}$ \\
\hline & $(0.046)$ & $(0.020)$ & $(69.503)$ & $(0.554)$ & $(1.029)$ & $(0.407)$ \\
\hline & {$[0.000]$} & {$[0.861]$} & {$[0.000]$} & {$[0.487]$} & {$[0.989]$} & {$[0.350]$} \\
\hline \multirow[t]{3}{*}{ Section $8 \mathrm{v}$ Control } & $0.189^{* * *}$ & -0.00736 & $239.3^{* * *}$ & $-0.75^{* * *}$ & $-0.164^{* *}$ & -0.0963 \\
\hline & $(0.031)$ & $(0.019)$ & $(39.107)$ & $(0.287)$ & $(0.072)$ & $(0.483)$ \\
\hline & {$[0.000]$} & {$[0.693]$} & {$[0.000]$} & {$[0.009]$} & {$[0.022]$} & {$[0.842]$} \\
\hline Control Group Mean & 0.0502 & 0.0708 & 1.902 & 58.54 & 5.155 & 2632 \\
\hline Observations & 41615 & 41615 & 41615 & 41615 & 46851 & 46851 \\
\hline \multicolumn{7}{|c|}{ Children: Ages $13-17$ years at $R A$} \\
\hline \multirow[t]{3}{*}{ Experimental v Control } & $0.0763^{\diamond \diamond}$ & $-0.015^{\diamond}$ & $194.7^{* \diamond}$ & 0.074 & $0.0763^{\diamond}$ & $0.352^{\diamond \diamond}$ \\
\hline & $(0.040)$ & $(0.087)$ & $(111.224)$ & $(0.516)$ & $(0.429)$ & $(0.685)$ \\
\hline & {$[0.058]$} & {$[0.864]$} & {$[0.080]$} & {$[0.886]$} & {$[0.859]$} & {$[0.608]$} \\
\hline \multirow[t]{3}{*}{ Section 8 v Control } & 0.0537 & -0.0334 & 76.6 & -0.132 & $0.0314^{\dagger}$ & 0.131 \\
\hline & $(0.045)$ & $(0.057)$ & $(216.688)$ & $(0.402)$ & $(0.410)$ & $(1.710)$ \\
\hline & {$[0.234]$} & {$[0.556]$} & {$[0.724]$} & {$[0.743]$} & {$[0.939]$} & {$[0.939]$} \\
\hline Control Group Mean & 0.0228 & -0.0517 & 1.399 & 57.95 & 3.910 & 2790 \\
\hline Observations & 24216 & 24216 & 24216 & 24216 & 25942 & 25942 \\
\hline \multicolumn{7}{|l|}{ Adults: $18+$ at $R A$} \\
\hline \multirow[t]{3}{*}{ Experimental v Control } & $0.260^{* * * \diamond}$ & $0.00615^{\diamond}$ & $380.9^{* * * \diamond}$ & 0.165 & $0.0647^{\diamond}$ & $-0.0156^{\infty}$ \\
\hline & $(0.025)$ & $(0.071)$ & $(62.247)$ & $(1.904)$ & $(0.144)$ & $(0.153)$ \\
\hline & {$[0.000]$} & {$[0.931]$} & {$[0.000]$} & {$[0.931]$} & {$[0.654]$} & {$[0.919]$} \\
\hline \multirow[t]{3}{*}{ Section 8 v Control } & $0.0686^{* * *}$ & -0.0162 & $181.9 * * *$ & -0.437 & -0.0367 & 0.219 \\
\hline & $(0.011)$ & $(0.017)$ & $(29.726)$ & $(0.384)$ & $(0.041)$ & $(0.224)$ \\
\hline & {$[0.000]$} & {$[0.327]$} & {$[0.000]$} & {$[0.255]$} & {$[0.372]$} & {$[0.327]$} \\
\hline Control Group Mean & -0.0273 & -0.104 & 1.326 & 58.06 & 3.540 & 2715 \\
\hline Observations & 59542 & 59542 & 59542 & 59542 & 63410 & 63410 \\
\hline
\end{tabular}

Note: This table reports the difference in means for recipients of Experimental or Section 8 vouchers relative to the control group. The mean of the outcome variable in the control group is reported at the bottom of each respective column. Per comparison p-values are reported in parentheses, and family-wise error rate adjusted p-values are reported in square brackets under each estimate. See text for more details. The symbol $\dagger$ indicates that the estimate differs significantly from the estimate among those randomized as young children. The symbol $\diamond$ indicates that the estimate differs significantly from the estimate of the effect of the Section 8 treatment arm. Significance levels: $*=10$ percent; ${ }^{* *}=5$ percent; $* * *=1$ percent 


\section{REFERENCES}

Abel, A. (1990). Asset prices under habit formation and catching up with the joneses. American Economic Review 80(2), 38-42.

Adams, W., L. Einav, and J. Levin (2009). Liquidity constraints and imperfect information in subprime lending. American Economic Review 99(1), 49-84.

Agarwal, S., V. Mikhed, and B. Scholnick (2019). Peers' income and financial distress: Evidence from lottery winners and neighboring bankruptcies. forthcoming, Review of Financial Statistics.

Anderson, M. (2012). Multiple inference and gender differences in the effects of early intervention: A reevaluation of the abecedarian, perry preschool, and early training projects. Journal of the American Statistical Association 103(484), 1481-1495.

Angrist, J. D., G. W. Imbens, and D. B. Rubin (1996). Identification of causal effects using instrumental variables. Journal of the American statistical Association 91(434), 444-455.

Banerjee, A. V. (1992, 08). A Simple Model of Herd Behavior*. The Quarterly Journal of Economics 107(3), 797-817.

Beer, R., F. Ionescu, and G. Li (2018). Are income and credit scores highly correlated? FEDS Notes. Washington: Board of Governors of the Federal Reserve System, https://doi.org/10. $17016 / 2380-7172.2235$

Bergman, P., R. Chetty, S. DeLuca, N. Hendren, L. Katz, and C. Palmer (2019). Creating Moves to Opportunity: Experimental Evidence on Barriers to Neighborhood Choice. NBER Working Paper 26164 .

Bernheim, B. D. (1994). A theory of conformity. Journal of Political Economy 102(5), 841-877.

Bertrand, M. and A. Morse (2011). Information disclosure, cognitive biases, and payday borrowing. Journal of Finance 66(6), 18651893.

Bertrand, M. and A. Morse (2016). Trickle-down consumption. Review of Economics and Statistics 5(98), 863879 . 
Bhutto, N. (2014). Payday loans and consumer financial health. Journal of Banking and Finance 47, 230-242.

Brevoort, K., P. Grimm, and M. Kambara (2015). Data point: Credit invisibles. CFPB Report. Brevoort, K., D. Grodzicki, M. Hackmann, and S. Koulayev (2019). The credit consequences of unpaid medical bills. NBER Working Paper 24002.

Brown, J., Z. Ivkovic, P. Smith, and S. Weisbenner (2008). Neighbors matter: Causal community effects and stock market participation. The Journal of Finance 63(3), 1509-1531.

Brown, J. R., J. A. Cookson, and R. Z. Heimer (2019). Growing up without finance. Journal of Financial Economics.

Burke, K., J. Leary, and J. Wang (2016). Information disclosure and payday lending in texas. Working Paper.

Bursztyn, L., F. Ederer, B. Ferman, and N. Yuchtman (2014). Understanding mechanisms underlying peer effects: Evidence from a field experiment in financial decisions. Econometrica 82(3), 12731301 .

Campbell, J. Y. and J. H. Cochrane (1999). By force of habit: A consumptionbased explanation of aggregate stock market behavior. Journal of Political Economy 107(2), 205-251.

Chetty, R., N. Hendren, and L. Katz (2016). The effects of exposure to better neighborhoods on children: New evidence from the moving to opportunity experiment. American Economic Review 106(4), 855-902.

Cohen-Cole, E. and B. Duygan-Bump (2008). Household bankruptcy decision: The role of social stigma vs information sharing. Working Paper, Federal Reserve Bank of Boston.

Cookson, J. A., E. Gilje, and R. Heimer (2019). Shale shocked: The long run effect of income on household debt. Working Paper.

Dobbie, W., P. Goldsmith-Pinkham, N. Mahoney, and J. Song (2017). Bad credit, no problem? credit and labor market consequences of bad credit reports. Working Paper. 
Dobbie, W., P. Goldsmith-Pinkham, and C. S. Yang (2017). Consumer bankruptcy and financial health. The Review of Economics and Statistics 99(5), 853-869.

Dobbie, W. and P. Skiba (2013). Information asymmetries in consumer credit markets: Evidence from payday lending. American Economic Journal: Applied Economics 5(4), 256-82.

Dobbie, W. and J. Song (2015). Debt relief and debtor outcomes: Measuring the effects of consumer bankruptcy protection. American Economic Review 105(3), 12721311.

Duflo, E. and E. Saez (2012). The role of information and social interactions in retirement plan decisions: Evidence from a randomized experiment. Quarterly Journal of Economics 118(3), $815-842$.

Ellison, G. and D. Fudenberg (1993). Rules of thumb for social learning. Journal of Political Economy 101(4), 612-643.

Fay, S., E. Hurst, and M. White (2002). The household bankruptcy decision. American Economic Review 92(3), 706-718.

Finkelstein, A., M. Gentzkow, and H. Williams (2016). Sources of geographic variation in health care: Evidence from patient migration. The Quarterly Journal of Economics 4(131), 1681-1726.

Finkelstein, A., S. Taubman, B. Wright, M. Bernstein, J. Gruber, J. Newhouse, H. Allen, and K. Baicker (2012). The oregon health insurance experiment: Evidence from the first year. Quarterly Journal of Economics 127(3), 1057-1106.

Gross, D. and N. Souleles (2002). Explaining the increase in bankruptcy and delinquency: Stigma versus risk-composition. Review of Financial Studies 15(1), 319-347.

Gross, T., M. Notowidigdo, and J. Wang (2018). The marginal propensity to consumer over the business cycle. Working Paper.

Hong, H., J. D. Kubik, and J. C. Stein (2004). Social interaction and stock-market participation. The Journal of Finance 59(1), 137-163.

Kling, J., J. Liebman, and L. Katz (2007). Experimental analysis of neighborhood effects. Econometrica $75(1), 83-119$. 
Lieber, E. M. and W. Skimmyhorn (forthcoming). Peer effects in financial decision making. Journal of Public Economics.

Ludwig, J., G. Duncan, L. Gennetian, L. Katz, R. Kessler, J. Kling, and L. Sanbonmatsu (2012). Neighborhood effects on the long-term well-being of low-income adults. Science 337(601), 15051510.

Ludwig, J., G. Duncan, L. Gennetian, L. Katz, R. Kessler, J. Kling, L. Sanbonmatsu, and T. McDade (2011). Neighborhoods, obesity, and diabetes a randomized social experiment. New England Journal of Medicine 365, 1509-1519.

Miller, S., L. Hu, R. Kaestner, B. Mazumder, and A. Wong (2018). The aca medicaid expansion in michigan and financial health. Working paper.

Miller, S. and C. Soo (2018). Does increasing formal credit access reduce payday borrowing? Working Paper.

Orr, L. L., J. D. Feins, R. Jacob, E. Beecroft, L. Sanbonmatsu, L. F. Katz, J. B. Liebman, and J. R. Kling (2003). Moving to opportunity for fair housing demonstration program: Interim impacts evaluation. U.S. Department of Housing and Urban Development, Office of Policy Development and Research.

Rhine, S. L. W., W. H. Greene, and M. Toussaint-Comeau (2006). The importance of check-cashing businesses to the unbanked: Racial/ethnic differences. Review of Economics and Statistics 1(88), $146-157$.

Romano, J. P. and M. Wolf (2016). Efficient computation of adjusted p-values for resampling-based stepdown multiple testing. Statistics and Probability Letters 113, 38-40.

Sanbonmatsu, Lisa, J. L. L. F. K. L. A. G. G. J. D. R. C. K. E. A. T. M. and S. T. Lindau (2011). Moving to opportunity for fair housing demonstration program: Final impacts evaluation. U.S. Department of Housing and Urban Development, Office of Policy Development and Research.

Westfall and Young (1993). Resampling-Based Multiple Testing: Examples and Methods for PValue Adjustment. New York Wiley. 


\title{
Do Neighborhoods Affect Credit Market Decisions of Low-Income Borrowers? Evidence from the Moving to Opportunity Experiment
}

\author{
Internet Appendix
}

Sarah Miller Cindy K. Soo

\section{Appendix A. Calculation of adjusted p-values}

We calculate p-values that are adjusted to account for the fact that we examine multiple outcomes within broad domains ("families"). We group outcomes into families based on topic: payday borrowing, delinquency, debt, and public records. The method that we use controls the probability that we incorrectly reject at least one true null hypothesis within a family of outcomes to the level of the test (e.g., 5 percent). We calculate these p-values using a free step-down re-sampling algorithm, following Kling et al. (2007), Anderson (2012), Finkelstein et al. (2012) and others. This algorithm and its properties are described in greater detail in Westfall and Young (1993) and Romano and Wolf (2016). In places where we report standard errors, we derive these from the implied t-statistic associated with the p-values (either adjusted or unadjusted as noted in the text) in order to have a consistent method of inference throughout the paper. The algorithm is implemented as follows:

1. We generate the original treatment effect for each outcome $j, \beta_{1} \ldots \beta_{m}$, and the original pvalues, $p_{1} \ldots p_{m}$, using Huber-White standard errors clustered at the family level and order these outcomes by significance, 1 to $\mathrm{m}$.

2. We re-sample families from the data with replacement and re-estimate treatment effects for each outcome $\left(\beta_{1}^{*}, \ldots, \beta_{m}^{*}\right)$.

3. We generate $\mathrm{p}$-values under the null hypothesis by testing $\beta_{j}^{*}=\beta_{j}$ for each $j=1 \ldots m$ and denote each p-value as $p_{j}^{*}$.

4. We enforce the significance ordering of our original inference by computing $p_{j}^{* *}=$ $\min \left(p_{j}^{*}, p_{j+1}^{*}, \ldots, p_{m}^{*}\right)$, where $\mathrm{j}$ denotes the original significance rank of the outcome, with $\mathrm{j}=$ 1 being the most significant and $\mathrm{j}=\mathrm{m}$ the least significant. This is referred to as enforcing monotonicity. 
5. We repeat steps 2 through 4999 times, generating many $p_{j}^{* *}$ s.

6 . We add up the number of times that $p_{j}^{* *}<p_{j}$. Call the total number $S_{j}$. We then calculate $p_{j}^{f w e r}=S_{j} / 1000$.

7. We enforce monotonicity a second time by defining $p_{j}^{f w e r}=\max \left(p_{1}^{f w e r *}, p_{2}^{f w e r *}, \ldots, p_{j}^{f w e r *}\right)$. This ensures that larger unadjusted p-values always correspond to larger adjusted p-values.

For the unadjusted p-value, we simply calculate fraction of $p_{j}^{*}$ that fall below $p_{j}$, without any monotonicity enforcement, following, e.g. Romano and Wolf (2016). 


\section{Appendix B. Estimating Convergence to Neighbors}

In order to assess the role of peer effects in driving our results, we systematically examine whether MTO participants who moved to lower income neighborhoods behaved more like their new neighbors as a result of the move. This is not obvious from the direct effects of the program, as reported in Tables II and III, because these estimates do not incorporate information on the behavior of neighbors. Since individuals in low poverty neighborhoods do not necessarily have better repayment behavior than those in high poverty neighborhoods, it is necessary to incorporate information about MTO participants' neighbors. In order to do so, we define the difference between voucher recipients' neighbors and the control group for each outcome $y$ as

$$
\Delta_{y, g}=\bar{y}_{n, g}-\bar{y}_{c}
$$

where $\bar{y}_{n, g}$ is the average of outcome $y$ among the neighbors of each treatment group $g$. Large values of $\Delta_{y}$ mean that voucher recipients have neighbors that look very different from the control group on outcome $y$, whereas small values of $\Delta_{y}$ indicate that voucher recipients' neighbors are not very different from the control group. We then re-scale our estimates of $\beta_{1}$ from equation (1) by this $\Delta$ by estimating

$$
Y_{i}=\beta_{0}+\tilde{\beta}_{1} \Delta_{y, \exp } \times \operatorname{Exp}_{i}+\tilde{\beta}_{2} \Delta_{y, \sec 8} \times S e c 8_{i}+\beta_{s}+\epsilon_{i}
$$

Note that this approach is similar to the one used in Finkelstein et al. (2016). Our estimates

of $\tilde{\beta}_{1}$ and $\tilde{\beta}_{2}$ are presented graphically in Figure A1 and A2 respectively. Asterisks indicate that $\tilde{\beta}$ differs significant from zero. We exclude one outcome for those who were randomized at ages 13 to 17 , the use of storefront payday loan products, because the size of this estimate is very large once scaled by $\Delta_{y}$ and renders the other estimates difficult to read.

Comparing across all three panels of each figure, we observe evidence that the only age group within the Experimental treatment arm that appeared to move systematically towards their neighbors were those who were randomized when under age 13. This group moved closer to their neighbors for 10 of the 13 outcomes considered; of these, 5 outcomes show statistically significant 
convergence towards neighbors ${ }^{26}$ In contrast, those randomized later in childhood in the Experimental group show, if anything, divergence from their neighbors in the low poverty areas relative to what they would have experienced had they been randomized into the control group. Among those randomized into the Experimental group in adulthood, there does not appear to be a consistent pattern, with evidence of convergence for some outcomes such as the amount of credit available, and divergence for other outcomes such as the credit score.

We observe a similar pattern in the Section 8 group for those randomized at younger ages, where most outcomes show convergence towards neighbors. In contrast to the Experimental group, those randomized later in childhood and adulthood show some evidence of convergence among delinquency outcomes such as judgements. Interestingly, those in the Section 8 group who were randomized in adulthood reduce their amount past due so much that they exhibit much lower levels of delinquency than their neighbors, resulting in them being farther away from the delinquency outcomes of their neighbors than the control group.

\footnotetext{
${ }^{26}$ Note that these estimates are adjusted for multiple comparisons using the method employed throughout the paper.
} 


\section{Appendix C. Data Appendix}

We present descriptive statistics about our matched dataset, which we use to examine the impact of MTO on credit outcomes of participants, and the dataset of neighborhood characteristics, which we use to explore mechanisms, in Tables A8 and A9, In the first column of these tables, we list the variables that are used in the analysis. The second column provides a short definition of each of these variables. In the third column, we report the number of observations we observe for these variables. Note that the number of observations is different for payday loan outcomes, which we observe for 2014 through 2017, than for most of our credit report outcomes, which we observe through 2001 through 2017. In addition, some credit report variables are only available beginning in 2007 (Judgement Amount and Tax Liens). The next five columns show the mean, standard deviation, and 25th, 50th, and 75th percentiles of the variable. 
Figure A1. Convergence to Neighbors: Experimental Group

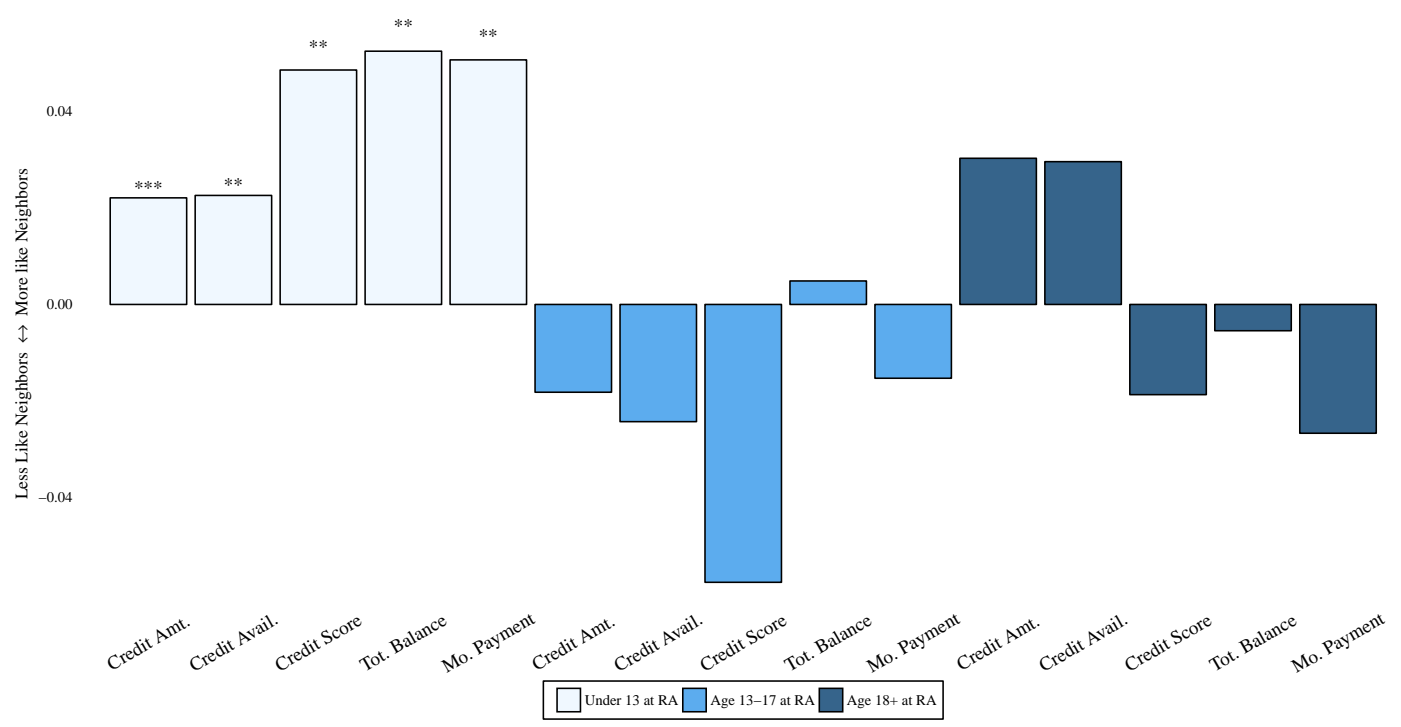

(a) Credit Outcomes, Experimental Group

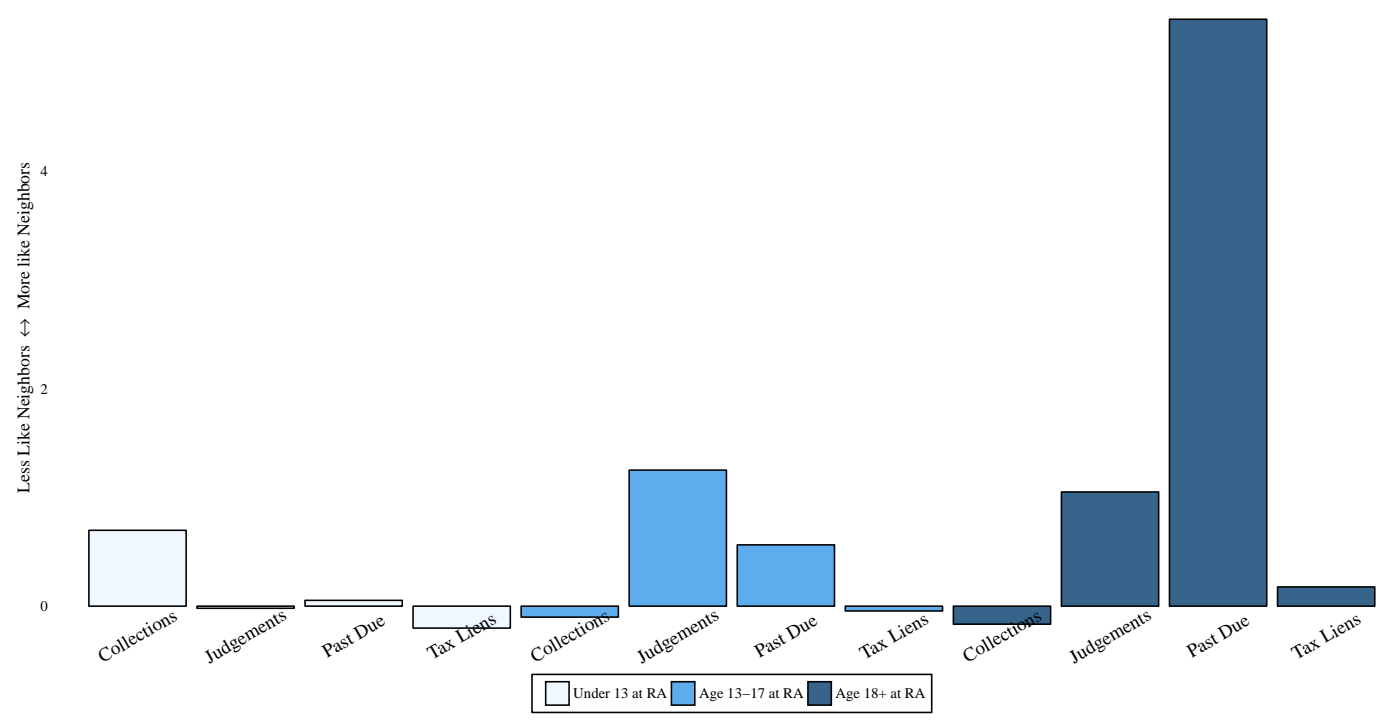

(b) Delinquency Outcomes, Experimental Group

Note: These figures show the estimates of MTO participants' convergence towards the outcomes of the residents of their zip codes, with positive values indicating the MTO participants behave more like their neighbors and negative values indicating they behave less like their neighbors. See text for more details. Significance levels: * $=10$ percent; $* *=5$ percent $* * *=1$ percent. 
Figure A2. Convergence to Neighbors: Section 8 Group

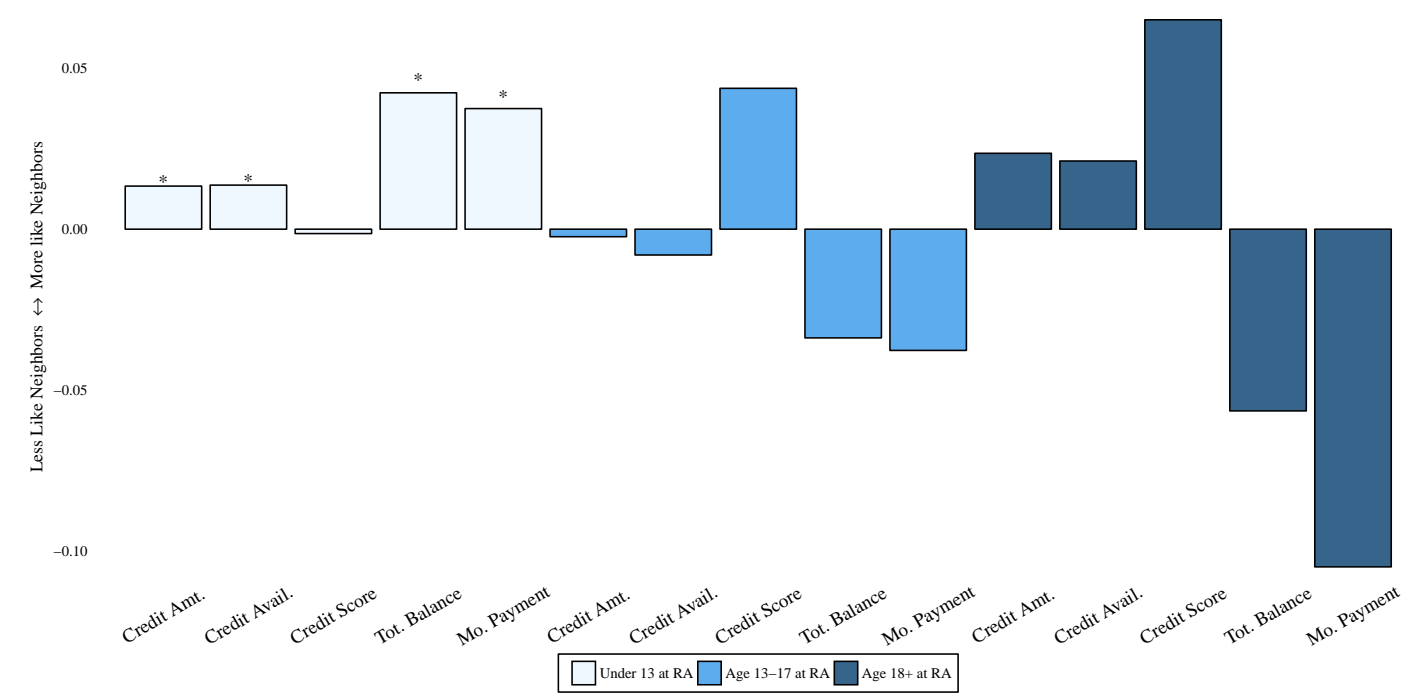

(a) Credit Outcomes, Section 8 Group

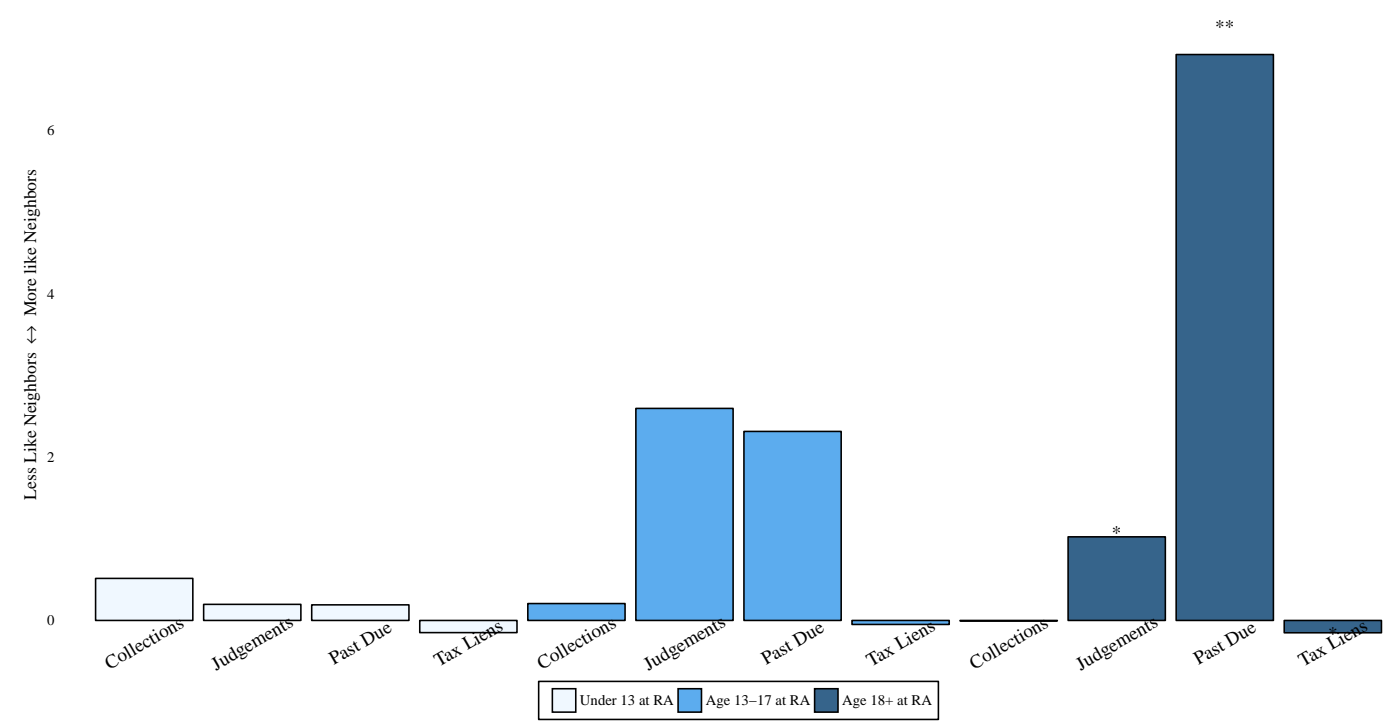

(b) Delinquency Outcomes, Section 8 Group

Note: These figures show the estimates of MTO participants' convergence towards the outcomes of the residents of their zip codes, with positive values indicating the MTO participants behave more like their neighbors and negative values indicating they behave less like their neighbors. See text for more details. Significance levels: * $=10$ percent; $* *=5$ percent $* * *=1$ percent. 
Figure A3. The Impact of Neighborhood on Outcomes at Age 24+, by Age at Random Assignment

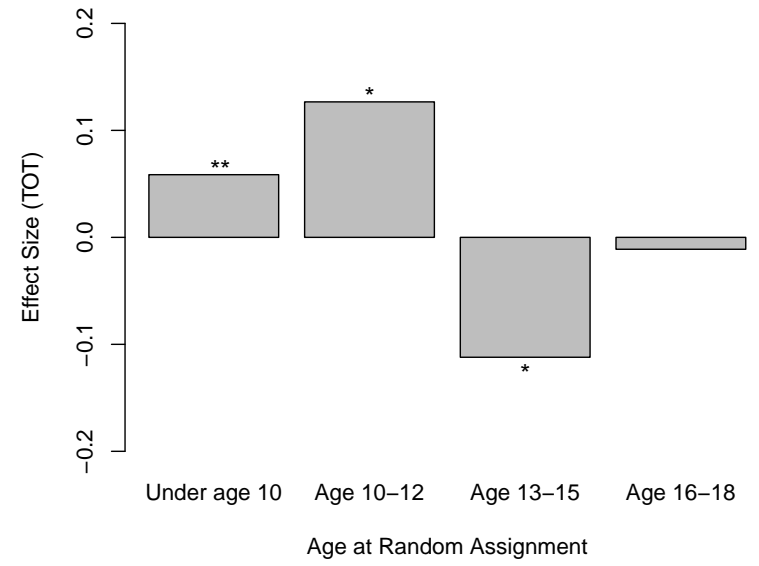

(a) Credit Index, Experimental Group

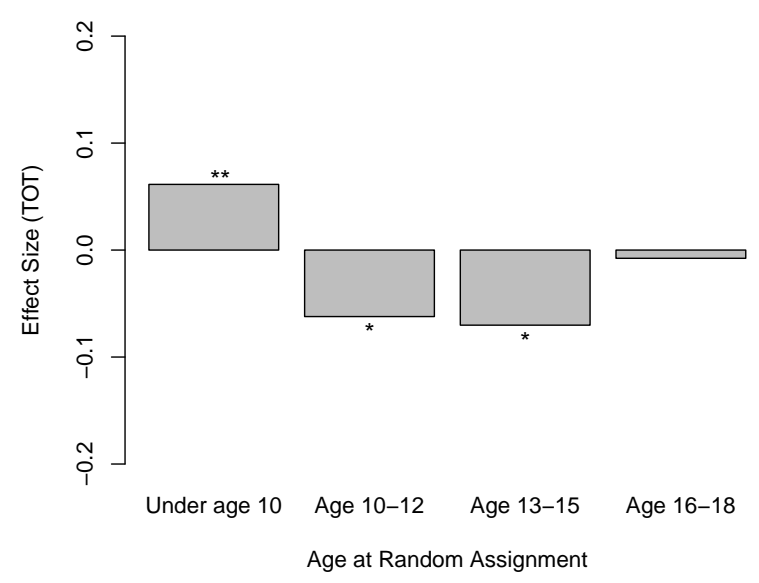

(c) Credit Index, Section 8 Group

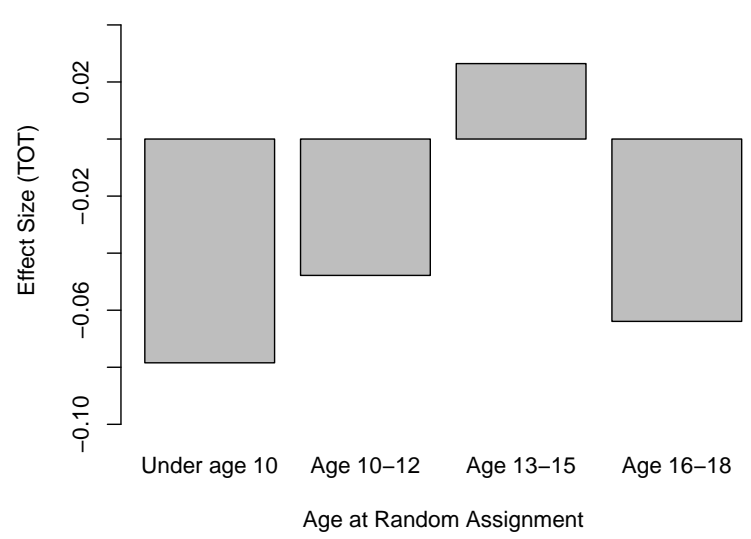

(b) Delinquency Index, Experimental Group

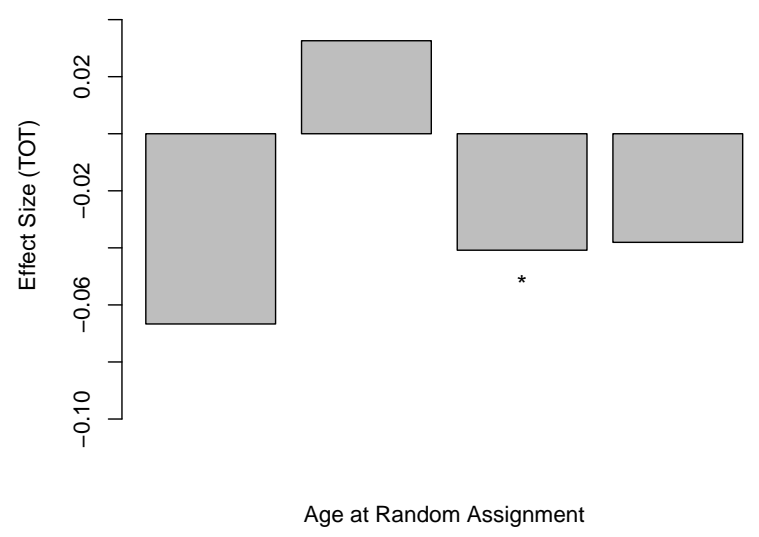

(d) Delinquency Index, Section 8 Group

Note: These figures show the TOT estimate of being randomized to each voucher arm at different ages. See text for more details. Significance levels: $*=10$ percent; $* *=5$ percent; $* * *=1$ percent. 
Figure A4. The Impact of Neighborhood by Age Observed in Credit Record (Blue=Under 13 at Random Assignment; Green=Age 13-17 at Random Assignment)

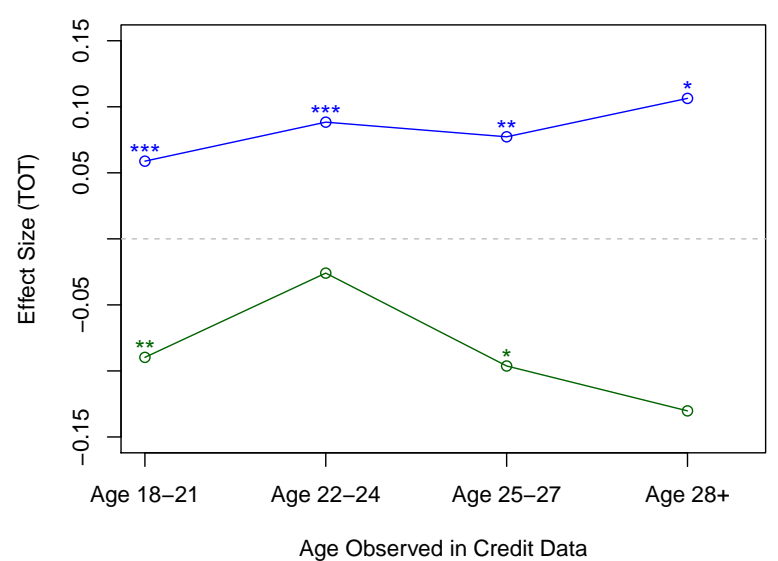

(a) Credit Index, Experimental Group

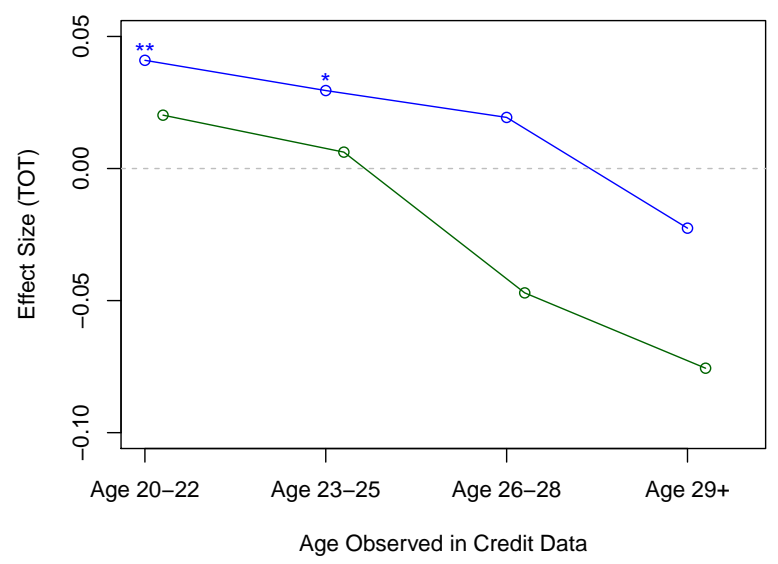

(c) Credit Index, Section 8 Group

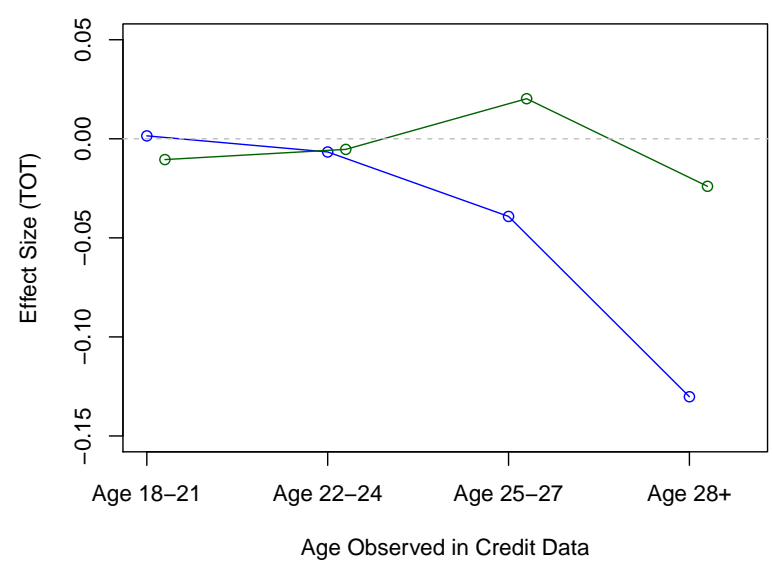

(b) Delinquency Index, Experimental Group

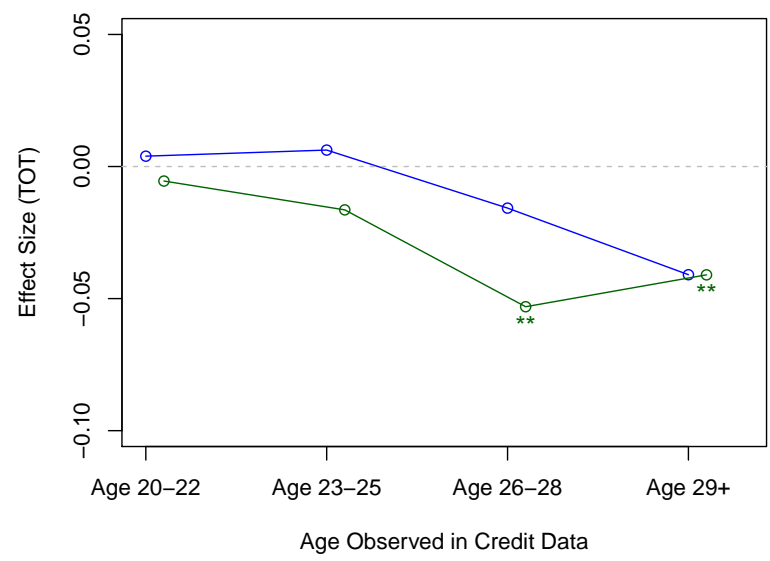

(d) Delinquency Index, Section 8 Group

Note: These figures show the TOT estimate of being randomized to each voucher arm as young (blue) or older (green) children at different ages in adulthood. See text for more details. Significance levels: $*=10$ percent; $* *=5$ percent; $* * *=1$ percent. 
Table A1 Match Rate Across Treatment Arms and Covariate Balance among Matched Sample

\begin{tabular}{|c|c|c|c|}
\hline & Control Group Mean & Experimental v Control & Section $8 \mathrm{v}$ Control \\
\hline \multicolumn{4}{|c|}{ 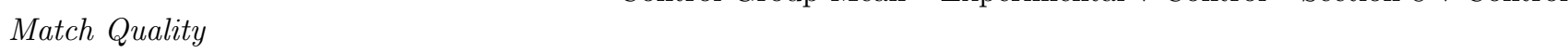 } \\
\hline Linked to Credit Data & 0.767 & $\begin{array}{c}0.003 \\
(0.009)\end{array}$ & $\begin{array}{c}0.006 \\
(0.009)\end{array}$ \\
\hline \# Years Observed in Credit Data & 8.55 & $\begin{array}{c}0.153 \\
(0.145)\end{array}$ & $\begin{array}{c}0.109 \\
(0.154)\end{array}$ \\
\hline \# Years Observed: Under 13 at RA & 6.23 & $\begin{array}{l}-0.02 \\
(0.153)\end{array}$ & $\begin{array}{c}0.06 \\
(0.165)\end{array}$ \\
\hline Number of MTO participants Linked & 3406 & 4360 & 3192 \\
\hline \multicolumn{4}{|l|}{ Baseline Characteristics } \\
\hline Household Head Completed GED & 0.175 & $\begin{array}{l}-0.0154 \\
(0.0166)\end{array}$ & $\begin{array}{r}-0.00737 \\
(0.0203)\end{array}$ \\
\hline Household Head Completed High School & 0.394 & $\begin{array}{c}0.000375 \\
(0.0216)\end{array}$ & $\begin{array}{c}0.0280 \\
(0.0265)\end{array}$ \\
\hline Household Head never married & 0.380 & $\begin{array}{c}0.0146 \\
(0.0207)\end{array}$ & $\begin{array}{l}-0.0172 \\
(0.0248)\end{array}$ \\
\hline Household Head had teenage birth & 0.260 & $\begin{array}{c}0.00415 \\
(0.0189)\end{array}$ & $\begin{array}{l}0.00927 \\
(0.0234)\end{array}$ \\
\hline Household victims of crime prior to MTO & 0.429 & $\begin{array}{c}0.0229 \\
(0.0211)\end{array}$ & $\begin{array}{r}-0.00395 \\
(0.0230)\end{array}$ \\
\hline Household Head Employed & 0.267 & $\begin{array}{l}0.00318 \\
(0.0195)\end{array}$ & $\begin{array}{l}0.00706 \\
(0.0238)\end{array}$ \\
\hline Household Head gets AFDC/TANF & 0.782 & $\begin{array}{c}0.0132 \\
(0.0168)\end{array}$ & $\begin{array}{l}0.00461 \\
(0.0180)\end{array}$ \\
\hline Household Head Female & 0.913 & $\begin{array}{l}-0.0119 \\
(0.0131)\end{array}$ & $\begin{array}{l}-0.0120 \\
(0.0135)\end{array}$ \\
\hline Household Head African American & 0.700 & $\begin{array}{c}0.00637 \\
(0.0173)\end{array}$ & $\begin{array}{c}-0.0341^{*} \\
(0.0201)\end{array}$ \\
\hline Household Head Hispanic & 0.283 & $\begin{array}{c}-0.00963 \\
(0.0175)\end{array}$ & $\begin{array}{c}0.0216 \\
(0.0201)\end{array}$ \\
\hline Move to get away from gangs or drugs & 0.782 & $\begin{array}{c}-0.00239 \\
(0.0175)\end{array}$ & $\begin{array}{l}-0.0197 \\
(0.0196)\end{array}$ \\
\hline Child susp./expelled in past 2 yrs. & 0.0685 & $\begin{array}{c}0.00965 \\
(0.00801)\end{array}$ & $\begin{array}{l}-0.00372 \\
(0.00823)\end{array}$ \\
\hline
\end{tabular}

Note: These summary statistics are baseline characteristics among individuals matched with a credit report only. This table presents only a sample of the full set of available covariates; see the appendix for the complete set of covariates. 
Table A2 Effect of MTO on Credit Outcomes, Adults and Children (ITT estimates)

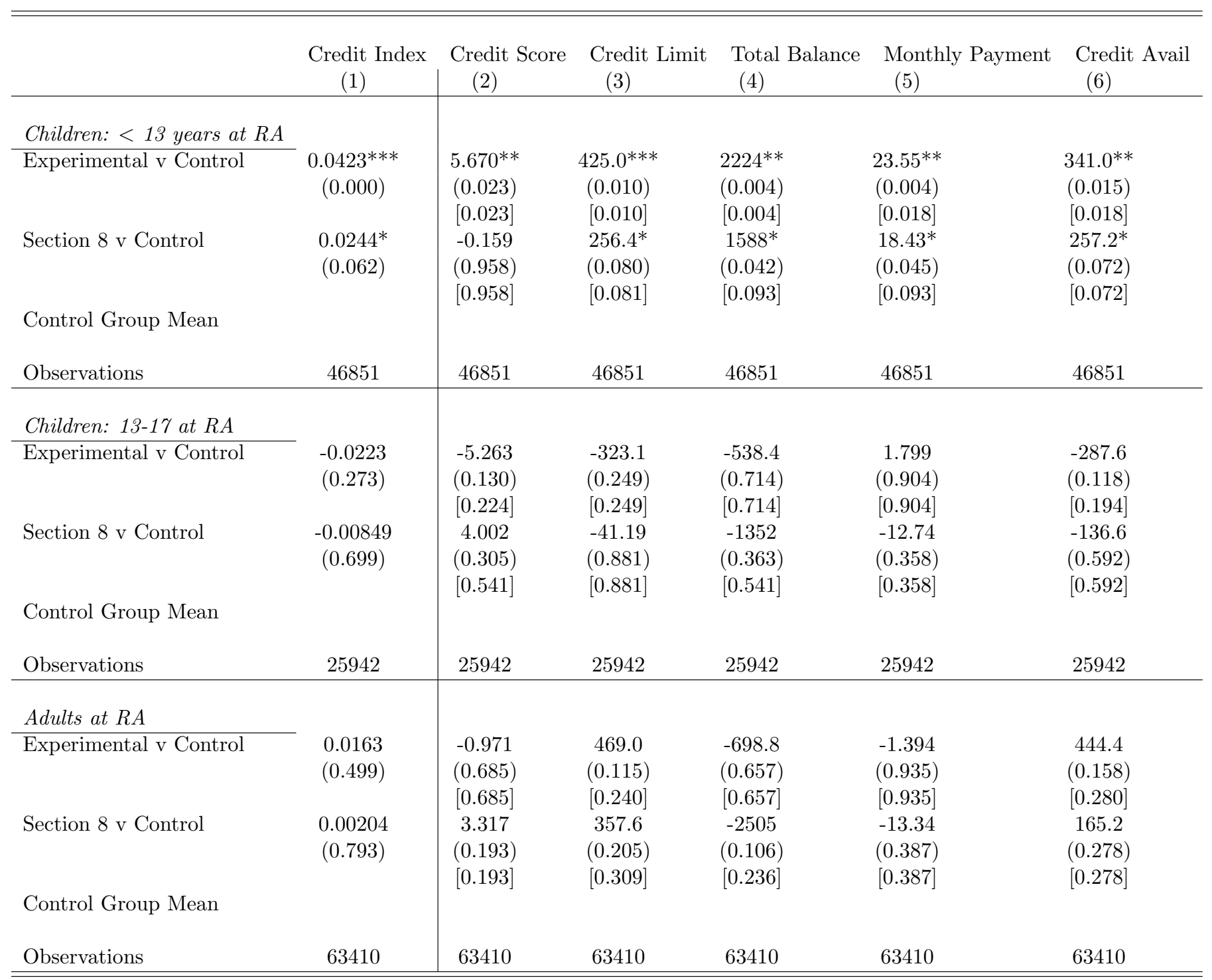

Note: This table reports the difference in means for recipients of Experimental or Section 8 vouchers relative to the control group. The mean of the outcome variable in the control group is reported at the bottom of each respective column. Per comparison p-values are reported in parentheses, and family-wise error rate adjusted p-values are reported in square brackets under each estimate. See text for more details. Significance levels: $*=10$ percent; $* *=5$ percent; $* * *=1$ percent 
Table A3 Effect of MTO on Delinquency Outcomes, Adults and Children (ITT estimates)

\begin{tabular}{|c|c|c|c|c|c|}
\hline & $\begin{array}{l}\text { Delinquency Index } \\
\text { (1) }\end{array}$ & $\begin{array}{l}30 \text { Days Past Due } \\
(2)\end{array}$ & $\begin{array}{l}\text { Tax Liens } \\
(3)\end{array}$ & $\begin{array}{l}\text { Judgment Amount } \\
\text { (4) }\end{array}$ & $\begin{array}{l}\text { Collections } \\
(5)\end{array}$ \\
\hline \multicolumn{6}{|c|}{ Panel A: Age $<13$ years at $R A$} \\
\hline Experimental v Control & $\begin{array}{c}-0.0179 * \\
(0.057)\end{array}$ & $\begin{array}{l}34.51 \\
(0.457) \\
{[0.457]}\end{array}$ & $\begin{array}{l}-125.0 \\
(0.117) \\
{[0.321]}\end{array}$ & $\begin{array}{l}-6.409 \\
(0.921) \\
{[0.921]}\end{array}$ & $\begin{array}{l}-220.2 \\
(0.228) \\
{[0.321]}\end{array}$ \\
\hline Section 8 v Control & $\begin{array}{c}-0.00648 \\
(0.469)\end{array}$ & $\begin{array}{l}122.9 \\
(0.191) \\
{[0.476]}\end{array}$ & $\begin{array}{l}{[-89.81} \\
(0.151)\end{array}$ & $\begin{array}{c}{[7.621]} \\
(0.547) \\
{[0.547]}\end{array}$ & $\begin{array}{l}{[0.021]} \\
-172.3 \\
(0.256)\end{array}$ \\
\hline \multicolumn{6}{|l|}{ Control Group Mean } \\
\hline Observations & 46851 & 46851 & 46851 & 42654 & 46851 \\
\hline \multicolumn{6}{|c|}{ Panel B: Ages $13-17$ years at $R A$} \\
\hline Experimental v Control & $\begin{array}{c}-0.00477 \\
(0.580)\end{array}$ & $\begin{array}{l}-58.10 \\
(0.674) \\
{[0.674]}\end{array}$ & $\begin{array}{l}-24.64 \\
(0.527) \\
{[0.527]}\end{array}$ & $\begin{array}{l}-96.90 \\
(0.554) \\
{[0.784]}\end{array}$ & $\begin{array}{l}67.18 \\
(0.431) \\
{[0.784]}\end{array}$ \\
\hline Section 8 v Control & $\begin{array}{c}-0.0258^{* * *} \\
(0.005)\end{array}$ & $\begin{array}{l}-246.6 \\
(0.106) \\
{[0.190]}\end{array}$ & $\begin{array}{l}-26.49 \\
(0.147) \\
{[0.147]}\end{array}$ & $\begin{array}{l}-281.4 \\
(0.114) \\
{[0.145]}\end{array}$ & $\begin{array}{l}-143.5 \\
(0.417) \\
{[0.417]}\end{array}$ \\
\hline \multicolumn{6}{|l|}{ Control Group Mean } \\
\hline Observations & 25942 & 25942 & 25942 & 18206 & 25942 \\
\hline \multicolumn{6}{|l|}{ Panel C: Adults at RA } \\
\hline Experimental v Control & $\begin{array}{c}0.00353 \\
(0.718)\end{array}$ & $\begin{array}{l}-84.55 \\
(0.477) \\
{[0.477]}\end{array}$ & $\begin{array}{l}77.86 \\
(0.056) \\
{[0.204]}\end{array}$ & $\begin{array}{l}-188.0 \\
(0.348) \\
{[0.348]}\end{array}$ & $\begin{array}{l}105.6 \\
(0.158) \\
{[0.368]}\end{array}$ \\
\hline Section 8 v Control & $\begin{array}{c}-0.0216^{* * *} \\
(0.002)\end{array}$ & $\begin{array}{c}-218.9^{* *} \\
(0.024)\end{array}$ & $\begin{array}{l}-66.24^{*} \\
(0.050)\end{array}$ & $\begin{array}{l}-183.8^{*} \\
(0.014)\end{array}$ & $\begin{array}{l}0.367 \\
(0.996)\end{array}$ \\
\hline \multicolumn{6}{|l|}{ Control Group Mean } \\
\hline Observations & 63410 & 63410 & 63410 & 41661 & 63410 \\
\hline
\end{tabular}

Note: This table reports the difference in means for recipients of Experimental or Section 8 vouchers relative to the control group. The mean of the outcome variable in the control group is reported at the bottom of each respective column. Per comparison p-values are reported in parentheses, and family-wise error rate adjusted p-values are reported in square brackets under each estimate. See text for more details. Significance levels: $*=10$ percent; $* *=5$ percent; $* * *=1$ percent 
Table A4 Effect of MTO on Payday Outcomes, Adults and Children (ITT estimates)

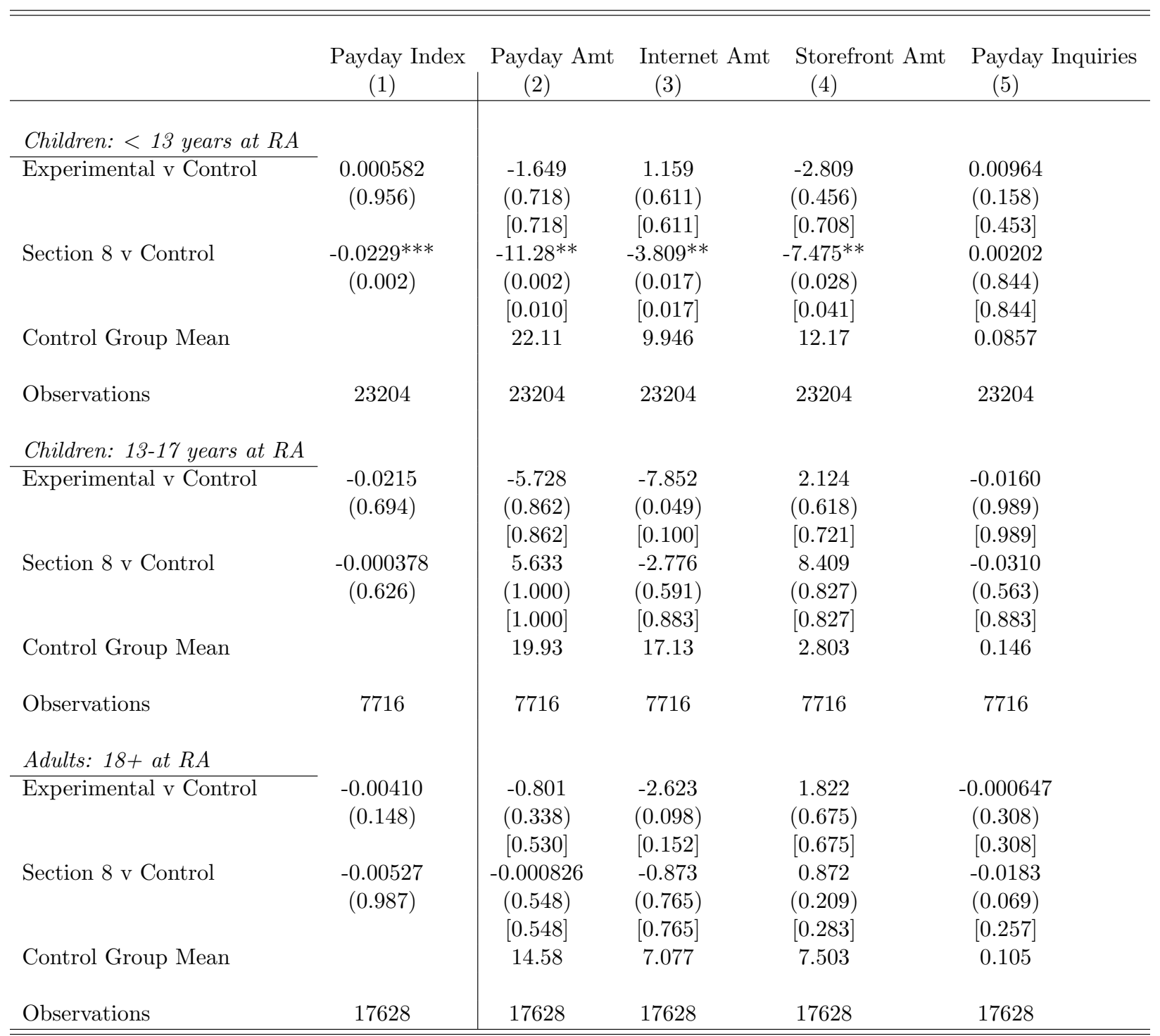

Note: This table reports the difference in means for recipients of Experimental or Section 8 vouchers relative to the control group. The mean of the outcome variable in the control group is reported at the bottom of each respective column. Per comparison p-values are reported in parentheses, and family-wise error rate adjusted p-values are reported in square brackets under each estimate. See text for more details. Significance levels: * $=10$ percent; $* *=5$ percent; $* * *=1$ percent 
Table A5 Component Effects of Neighborhood Peer Credit Index

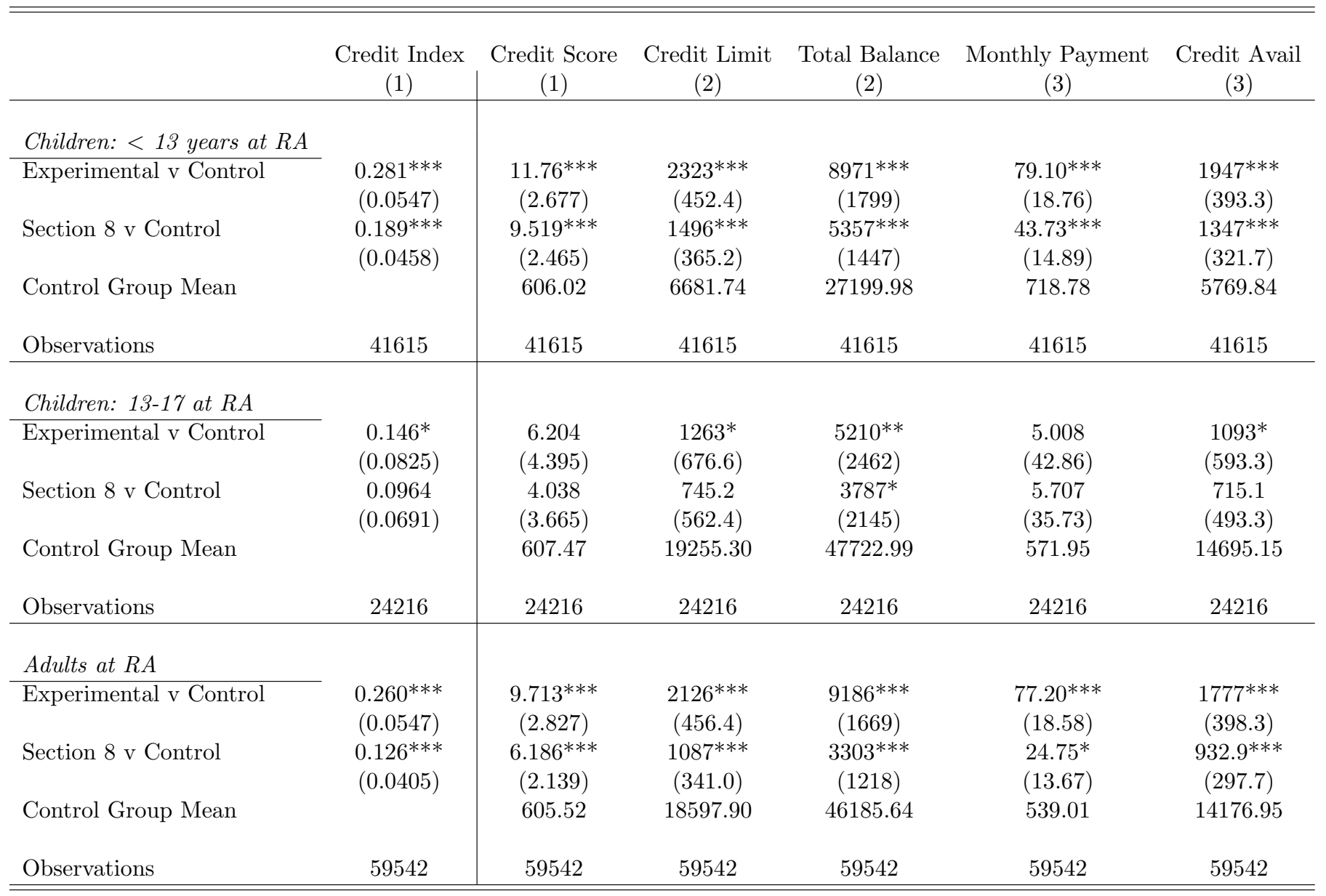

Note: This table reports the difference in means for recipients of Experimental or Section 8 vouchers relative to the control group. The mean of the outcome variable in the control group is reported at the bottom of each respective column. Per comparison p-values are reported in parentheses, and family-wise error rate adjusted p-values are reported in square brackets under each estimate. See text for more details. Significance levels: $*=10$ percent; $* *=5$ percent; $* * *=1$ percent 
Table A6 Component Effects of Neighborhood Peer Delinquency Index

\begin{tabular}{|c|c|c|c|c|c|}
\hline & $\begin{array}{c}\text { Delinquency Index } \\
(1)\end{array}$ & $\begin{array}{c}30 \text { Days Past Due } \\
(2)\end{array}$ & $\begin{array}{c}\text { Tax Liens } \\
(3) \\
\end{array}$ & $\begin{array}{c}\text { Judgment Amount } \\
(4)\end{array}$ & $\begin{array}{c}\text { Collections } \\
(5)\end{array}$ \\
\hline \multicolumn{6}{|c|}{ Children: $<13$ years at $R A$} \\
\hline Experimental v Control & $\begin{array}{l}0.00349 \\
(0.0287)\end{array}$ & $\begin{array}{l}-40.62 \\
(37.08)\end{array}$ & $\begin{array}{c}170.9^{* * *} \\
(62.32)\end{array}$ & $\begin{array}{l}72.63 \\
(47.85)\end{array}$ & $\begin{array}{c}-99.58^{* *} \\
(40.53)\end{array}$ \\
\hline Section 8 v Control & $\begin{array}{l}-0.00736 \\
(0.0256)\end{array}$ & $\begin{array}{l}-47.11 \\
(33.83)\end{array}$ & $\begin{array}{l}100.3^{*} \\
(56.84)\end{array}$ & $\begin{array}{l}94.10^{* *} \\
(46.76)\end{array}$ & $\begin{array}{c}-110.8 * * * \\
(32.35)\end{array}$ \\
\hline Control Group Mean & & 978.98 & 635.34 & 542.68 & 1328.20 \\
\hline Observations & 41615 & 41615 & 41615 & 41615 & 41615 \\
\hline \multicolumn{6}{|l|}{ Children: $13-17$ at $R A$} \\
\hline Experimental v Control & $\begin{array}{l}-0.0150 \\
(0.0426)\end{array}$ & $\begin{array}{l}-27.60 \\
(47.98)\end{array}$ & $\begin{array}{c}47.27 \\
(103.7)\end{array}$ & $\begin{array}{c}20.91 \\
(89.43)\end{array}$ & $\begin{array}{l}-21.18 \\
(59.53)\end{array}$ \\
\hline Section 8 v Control & $\begin{array}{l}-0.0334 \\
(0.0330)\end{array}$ & $\begin{array}{l}-16.53 \\
(40.32)\end{array}$ & $\begin{array}{c}5.449 \\
(80.81)\end{array}$ & $\begin{array}{l}-15.84 \\
(61.08)\end{array}$ & $\begin{array}{l}-58.81 \\
(46.07)\end{array}$ \\
\hline Control Group Mean & & 926.54 & 628.99 & 521.55 & 1327.54 \\
\hline Observations & 24216 & 24216 & 24216 & 24216 & 24216 \\
\hline \multicolumn{6}{|l|}{ Adults at $R A$} \\
\hline Experimental v Control & $\begin{array}{l}0.00615 \\
(0.0217)\end{array}$ & $\begin{array}{l}-17.01 \\
(29.77)\end{array}$ & $\begin{array}{c}55.95 \\
(40.90)\end{array}$ & $\begin{array}{c}67.11 \\
(41.03)\end{array}$ & $\begin{array}{l}-23.68 \\
(32.10)\end{array}$ \\
\hline Section 8 v Control & $\begin{array}{l}-0.0162 \\
(0.0164)\end{array}$ & $\begin{array}{c}-48.51^{* *} \\
(22.55)\end{array}$ & $\begin{array}{c}33.44 \\
(32.02)\end{array}$ & $\begin{array}{l}52.37^{*} \\
(27.53)\end{array}$ & $\begin{array}{l}-45.08^{*} \\
(24.33)\end{array}$ \\
\hline Control Group Mean & & 915.68 & 551.79 & 477.99 & 1279.16 \\
\hline Observations & 59542 & 59542 & 59542 & 59542 & 59542 \\
\hline
\end{tabular}

Note: This table reports the difference in means for recipients of Experimental or Section 8 vouchers relative to the control group. The mean of the outcome variable in the control group is reported at the bottom of each respective column. Per comparison p-values are reported in parentheses, and family-wise error rate adjusted p-values are reported in square brackets under each estimate. See text for more details. Significance levels: $*=10$ percent; $* *=5$ percent; $* * *=1$ percent 
Table A7 TOT Effects of MTO on Bankruptcy and Mortgage Outcomes

\begin{tabular}{|c|c|c|c|}
\hline & Any Mortgage & Mortgage Delinquency & Bankruptcy \\
\hline \multicolumn{4}{|l|}{ Children: Age $<13$ years at $R A$} \\
\hline \multirow[t]{2}{*}{ Experimental v Control } & $0.0222^{* *}$ & 0.00257 & 0.00996 \\
\hline & $(0.0101)$ & $(0.00292)$ & $(0.00894)$ \\
\hline \multirow[t]{2}{*}{ Section 8 v Control } & $0.0142^{*}$ & 0.00104 & -0.00314 \\
\hline & $(0.00744)$ & $(0.00220)$ & $(0.00688)$ \\
\hline Observations & 41615 & 41615 & 41615 \\
\hline \multicolumn{4}{|l|}{ Children: Ages $13-17$ years at $R A$} \\
\hline \multirow[t]{2}{*}{ Experimental v Control } & -0.00941 & -0.00149 & -0.0121 \\
\hline & $(0.0183)$ & $(0.00644)$ & $(0.0178)$ \\
\hline \multirow[t]{2}{*}{ Section 8 v Control } & -0.0167 & 0.00116 & 0.000858 \\
\hline & $(0.0142)$ & $(0.00513)$ & $(0.0185)$ \\
\hline Observations & 24216 & 24216 & 24216 \\
\hline \multicolumn{4}{|l|}{ Adults: $18+$ at $R A$} \\
\hline \multirow[t]{2}{*}{ Experimental v Control } & -0.00971 & 0.00321 & 0.00988 \\
\hline & $(0.0183)$ & $(0.00785)$ & $(0.0218)$ \\
\hline \multirow[t]{2}{*}{ Section 8 v Control } & -0.0182 & -0.00292 & 0.0295 \\
\hline & $(0.0167)$ & $(0.00548)$ & $(0.0192)$ \\
\hline Observations & 59542 & 59542 & 59542 \\
\hline
\end{tabular}

Note: This table reports the difference in means for recipients of Experimental or Section 8 vouchers relative to the control group. The mean of the outcome variable in the control group is reported at the bottom of each respective column. Per comparison p-values are reported in parentheses, and family-wise error rate adjusted p-values are reported in square brackets under each estimate. See text for more details. Significance levels: $*=10$ percent; $* *=5$ percent; $* * *=1$ percent 
Table A8 Summary Statistics: Primary Outcomes

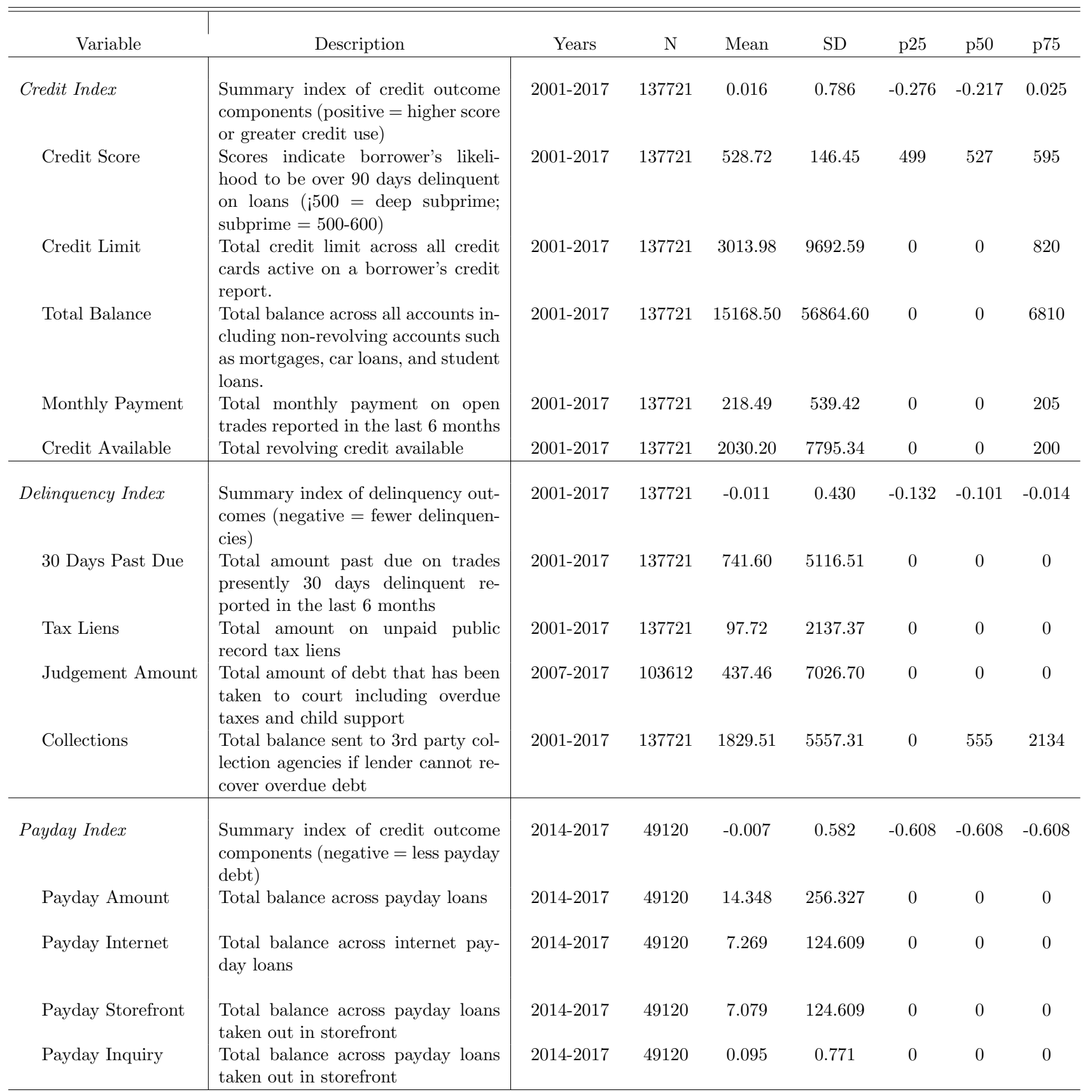

Note: This table reports summary statistics for the primary outcomes in Tables II-IV of our main analysis. Data sources for outcomes under the credit index and delinquency index are from Experian, and payday outcomes are from a subsidiary of Experian, Clarity Services. Details on these data sources can be found in Section I of the main paper. All data frequencies are annual, or aggregated to be annual for analysis. Note that if an individual is not matched to a credit record in a particular year, those observations are considered missing. Note that payday loans are only used by a small fraction of our sample (1-2\%) but this reflects a similar fraction of use by the population of low income, subprime borrowers as reported by the Survey of Consumer Finances. Thus, most borrowers in our sample take out 0 payday amounts. Furthermore as detailed in Section I, despite their broad coverage, the Clarity database may not cover all payday loans taken out by borrowers if their underwriting services are not utilized by the lender. 
Table A9 Summary Statistics: Neighborhood Outcomes

\begin{tabular}{|c|c|c|c|c|c|c|c|c|}
\hline Variable & Description & Years & $\mathrm{N}$ & Mean & $\mathrm{SD}$ & $\mathrm{p} 25$ & $\mathrm{p} 50$ & p75 \\
\hline Peer Credit Index & $\begin{array}{l}\text { Summary z-score of average peer } \\
\text { credit outcomes s. }\end{array}$ & $2001-2017$ & 126763 & 0.803 & 0.583 & 0.417 & 0.664 & 1.070 \\
\hline Peer Credit Score & $\begin{array}{l}\text { Average credit scores of peer resi- } \\
\text { dents across zipcodes MTO partici- } \\
\text { pants have lived in from 2001-2017. }\end{array}$ & $2001-2017$ & 126763 & 607.95 & 41.65 & 576.81 & 603.44 & 634.35 \\
\hline Peer Credit Limit & $\begin{array}{l}\text { Average credit limits of peer resi- } \\
\text { dents across zipcodes MTO partic- } \\
\text { ipants have lived in from 2001-2017. }\end{array}$ & $2001-2017$ & 126740 & 19566.63 & 7023.48 & 14544.02 & 18321.44 & 23223.75 \\
\hline Peer Total Balance & $\begin{array}{l}\text { Average total balance of peer resi- } \\
\text { dents across zipcodes MTO partici- } \\
\text { pants have lived in from 2001-2017. }\end{array}$ & $2001-2017$ & 126740 & 14968.90 & 6098.84 & 10462.17 & 13797.47 & 18114.42 \\
\hline Peer Monthly Payment & $\begin{array}{l}\text { Average minimum monthly pay- } \\
\text { ment of peer residents across zip- } \\
\text { codes MTO participants have lived } \\
\text { in from 2001-2017. }\end{array}$ & 2001-2017 & 126763 & 47555.70 & 29570.61 & 26485.75 & 40898.76 & 61381 \\
\hline Peer Credit Available & $\begin{array}{l}\text { Average additional credit available } \\
\text { of peer residents across zipcodes } \\
\text { MTO participants have lived in } \\
\text { from } 2001-2017 \text {. }\end{array}$ & $2001-2017$ & 126763 & 548.72 & 593.23 & 355.59 & 490.64 & 671.64 \\
\hline Peer Delinquency Index & $\begin{array}{l}\text { Summary z-score of average peer } \\
\text { delinquency outcomes. }\end{array}$ & $2001-2017$ & 126763 & 0.033 & 0.159 & -0.040 & 0.012 & 0.075 \\
\hline Peer 30 Days Past Due & $\begin{array}{l}\text { Average amount } 30 \text { days past due of } \\
\text { peer residents across zipcodes MTO } \\
\text { participants have lived in from 2001- } \\
2017 \text {. }\end{array}$ & $2001-2017$ & 126763 & 978.98 & 812.42 & 369.12 & 776.77 & 1352.63 \\
\hline Peer Tax Liens & $\begin{array}{l}\text { Average overdue taxes owed of peer } \\
\text { residents across zipcodes MTO par- } \\
\text { ticipan }\end{array}$ & $2001-2017$ & 126763 & 635.34 & 1530.55 & 151.63 & 355.49 & 693.23 \\
\hline Peer Judgement Amount & $\begin{array}{l}\text { Average amounts held in court of } \\
\text { peer residents across zipcodes MTO } \\
\text { participants have lived in from } 2007 \text { - } \\
2017 \text {. }\end{array}$ & $2007-2017$ & 92668 & 542.68 & 1257.28 & 162.33 & 332.92 & 631.90 \\
\hline Peer Collections & $\begin{array}{l}\text { Average amount in 3rd party col- } \\
\text { lections of peer residents across zip- } \\
\text { codes MTO participants have lived } \\
\text { in from 2001-2017. }\end{array}$ & $2001-2017$ & 126763 & 1328.20 & 776.30 & 802.57 & 1213.78 & 1740.58 \\
\hline Peer Expenditures & $\begin{array}{l}\text { Average credit card expenditures of } \\
\text { peer residents across zipcodes MTO } \\
\text { participants have lived in from 2001- } \\
2017 \text {. }\end{array}$ & $2001-2017$ & 126763 & 2800.38 & 1263.85 & 1914.46 & 2539.85 & 3474.11 \\
\hline Peer Utilization & $\begin{array}{l}\text { Average fraction of total credit uti- } \\
\text { lized in last } 6 \text { months of peer resi- } \\
\text { dents across zipcodes MTO partici- } \\
\text { pants have lived in from 2001-2017. }\end{array}$ & $2001-2017$ & 126751 & 58.18 & 7.19 & 53.39 & 58.53 & 63.31 \\
\hline Banks & $\begin{array}{l}\text { Number of traditional banking insti- } \\
\text { tutions across zipcodes MTO partic- } \\
\text { ipants have lived in from 2001-2017 }\end{array}$ & $2001-2017$ & 137721 & 4.362007 & 5.74011 & 0 & 3 & 6 \\
\hline Payday Stores & $\begin{array}{l}\text { Number of payday storefronts across } \\
\text { zipcodes MTO participants have } \\
\text { lived in from 2001-2017 }\end{array}$ & $2001-2017$ & 137721 & 1.529709 & 2.05981 & 0 & 1 & 2 \\
\hline
\end{tabular}

Note: This table reports summary statistics for the neighborhood outcomes in Table V of our main analysis. These outcomes represent the average credit or delinquency behavior of residents in the zip codes MTO participants move to from 2001 to 2017. Data sources for credit and delinquency neighborhood outcomes come from a 4 million random sample of credit reports obtained from Experian. Data source for the number of banks and payday stores are from Census Business Patterns. 